\title{
GENOMIC IDENTITY OF WHITE OAK SPECIES IN AN EASTERN NORTH AMERICAN SYNGAMEON ${ }^{1}$
}

\author{
Andrew L. Hipp, ${ }^{2,3 *}$ Alan T. Whittemore, ${ }^{4}$ \\ Mira Garner, ${ }^{2}$ Marlene Hahn, ${ }^{2}$ Elisabeth Fitzek, ${ }^{5}$ \\ Erwan Guichoux, ${ }^{6}$ Jeannine Cavender-Bares, ${ }^{7}$ \\ Paul F. Gugger, ${ }^{8}$ Paul S. Manos, ${ }^{9}$ Ian S. Pearse, ${ }^{10}$ \\ and Charles H. Cannon ${ }^{2}$
}

\section{Abstract}

The eastern North American white oaks, a complex of approximately 16 potentially interbreeding species, have become a classic model for studying the genetic nature of species in a syngameon. Genetic work over the past two decades has demonstrated the reality of oak species, but gene flow between sympatric oaks raises the question of whether there are conserved regions of the genome that define oak species. Does gene flow homogenize the entire genome? Do the regions of the genome that distinguish a species in one part of its range differ from the regions that distinguish it in other parts of its range, where it grows in sympatry with different species? Or are there regions of the genome that are relatively conserved across species ranges? In this study, we revisit seven species of the eastern North American white oak syngameon using a set of 80 single-nucleotide polymorphisms (SNPs) selected in a previous study because they show differences among, and consistency within, the species. We test the hypothesis that there exist segments of the genome that do not become homogenized by repeated introgression, but retain distinct alleles characteristic of each species. We undertake a range-wide sampling to investigate whether SNPs that appeared to be fixed based on a relatively small sample in our previous work are fixed or nearly fixed across the range of the species. Each of the seven species remains genetically distinct across its range, given our diagnostic set of markers, with relatively few individuals exhibiting admixture of multiple species. SNPs map back to all 12 Quercus linkage groups (chromosomes) and are separated from each other by an average of 7.47 million bp ( \pm 8.74 million bp, SD), but are significantly clustered relative to a random null distribution, suggesting that our SNP toolkit reflects genome-wide patterns of divergence while potentially being concentrated in regions of the genome that reflect a higher-than-average history of among-species divergence. This application of a DNA toolkit designed for the simple problem of identifying species in the field has two important implications. First, the eastern North American white oak syngameon is composed of entities that most taxonomists would consider "good species." Second, and more fundamentally, species in the syngameon are genetically coherent because characteristic portions of the genome remain divergent despite a history of introgression. Understanding the conditions under which some loci diverge while others introgress is key to understanding the origins and maintenance of global tree diversity.

Key words: Cohesion species, DNA genotyping toolkit, hybridization, introgression, Quercus, single-nucleotide polymorphism (SNP), syngameon.

1 This paper is based on a talk presented by the first author at the Missouri Botanical Garden's 65th Annual Fall Symposium. Portions of the introduction and conclusion are adapted from an essay published by the first author in the Journal of International Oaks (Hipp, 2015). The manuscript benefited from comments by Thibault Leroy. Data and analyses presented here have not been published elsewhere. The majority of collections and all of M. G.'s time were funded by USDA Agreement Number 58-8020-5-005, project number 8020-21000-070-03S, to A. L. H. and A. T. W. Leaf silhouettes were digitized in part by M. Kaproth. SNP data were generated with financial support of The Morton Arboretum's Center for Tree Science. Any use of trade, firm, or product names is for descriptive purposes only and does not imply endorsement by the U.S. Government.

2 The Morton Arboretum, Herbarium, 4100 Illinois Route 53, Lisle, Illinois 60532, U.S.A.

3 Integrative Research Center, The Field Museum, 1400 S Lake Shore Drive, Chicago, Illinois 60605, U.S.A.

4 U.S. National Arboretum, 3501 New York Avenue NE, Washington, D.C. 20002, U.S.A.

5 Universität Bielefeld, Department of Computational Biology, Center for Biotechnology - CeBiTec, Universitaetsstrasse 27, 33615 Bielefeld, Germany.

6 BIOGECO, INRA, Université Bordeaux, 33610 Cestas, France.

7 Department of Ecology, Evolution and Behavior, University of Minnesota, 1479 Gortner Avenue, Saint Paul, Minnesota 55108, U.S.A.

8 University of Maryland Center for Environmental Science, Appalachian Laboratory, 301 Braddock Road, Frostburg, Maryland 21532, U.S.A.

9 Department of Biology, Duke University, 130 Science Drive, Durham, North Carolina 27708, U.S.A.

10 U.S. Geological Survey, Fort Collins Science Center, 2150 Centre Avenue, Fort Collins, Colorado 80526, U.S.A.

* Author for correspondence: ahipp@mortonarb.org 
Hybridization and introgressive gene flow in oaks have long suggested the question of what constitutes an oak species. The 1867 edition of Gray's Manual of the Botany of the Northern United States (Gray, 1867), for example, reports five hybrids in oaks, ${ }^{1}$ and Wiegand (1935) notes that in this edition, "we find hybrids scarcely mentioned except in one genus, Quercus." In the early 20th century, studies of character segregation in first- and second-generation oak hybrids suggested that adaptive gene flow might contribute to range extensions in the southern live oak Q. virginiana Mill. (Ness, 1918; Allard, 1932; Yarnell \& Palmer, 1933). The roughly 100 years following Gray's 1867 edition saw a number of seminal papers, mostly dealing with the effects of interspecific hybridization on oak species origins, coherence, and evolutionary trajectories (e.g., Engelmann, 1876; Palmer, 1948; Muller, 1952).

In the mid-1970s, a trio of now-classic papers that focused on the eastern North American white oak syngameon set the stage for contemporary studies of oak species coherence. In 1975, James Hardin published an article in the Journal of the Arnold Arboretum reporting evidence of widespread gene flow among 16 white oaks of eastern North America (Hardin, 1975). At about the same time, a pair of articles in Taxon argued that gene flow in oaks is dominated by localized gene flow among individuals that are closely enough related to exchange genes, irrespective of species, rather than among populations within species (Burger, 1975; Van Valen, 1976). Because of ongoing gene flow and introgression, Burger and Van Valen argued, oak species cannot be defined by reproductive isolation. Rather, oak species represent ecologically discrete lineages with distinct evolutionary trajectories. "Species," Van Valen wrote, "are maintained for the most part ecologically, not reproductively." He and Burger both argued that local gene flow among sympatric populations of different species may exceed gene flow between geographically distant populations of single species, and that the capacity for interbreeding cannot therefore be the criterion by which we recognize oak species. Burger went so far as to suggest erecting subgenera or sections that are equivalent to reproductive species, but allowing our named species in oaks to represent ecologically and morphologically defined evolutionary lineages. The idea that gene flow is often insufficient to cause species to cohere across their range had been discussed previously
(Ehrlich \& Raven, 1969), but Burger and Van Valen seem to be making a stronger claim: oak species are delimited not reproductively, but ecologically. A measured skepticism about oak species is not uncommon among botanists even today, unsurprising in the face of ample evidence of introgression and gene flow (e.g., Whittemore \& Schaal, 1991; Dumolin-Lapegue et al., 1997; Dumolin-Lapegue \& Petit, 1999; Petit et al., 2003; Dodd \& Afzal-Rafii, 2004; Tovar-Sánchez \& Oyama, 2004; Craft \& Ashley, 2006; Lexer et al., 2006; Curtu et al., 2007; Hipp \& Weber, 2008; Chybicki \& Burczyk, 2010; Moran et al., 2012).

In the past two decades, the increased availability of single-locus DNA markers has stimulated investigation into the processes that maintain distinct species in the presence of interspecific hybridization (Kremer \& Hipp, in press). It is notable that different studies using singlelocus DNA markers have shown strikingly different patterns. Studies utilizing chloroplast DNA markers have generally yielded clear evidence of introgressive exchange of markers, with little if any clustering of individuals by species (Whittemore \& Schaal, 1991; Dumolin-Lapegue et al., 1997, 1999; Petit et al., 1997, 2003; Manos et al., 1999; Belahbib et al., 2001; Pham et al., 2017). Studies utilizing nuclear markers, on the other hand, have typically demonstrated that gene flow among species (Dodd \& Afzal-Rafii, 2004; Gömöry \& Schmidtová, 2007; de Casas et al., 2007; Eaton et al., 2015) is balanced by gene flow within species, promoting species cohesion (Whittemore \& Schaal, 1991; Muir et al., 2000; Muir \& Schlötterer, 2005; Lexer et al., 2006; Leroy et al., 2017, 2018).

Next-generation DNA sequencing (NGS) has made it practical to test more rigorous models of introgression history in oaks using much larger numbers of loci (e.g., Eaton et al., 2015; Leroy et al., 2017). Additionally, NGS has enabled economical development of genotyping toolkits for smaller applications. In a recent paper, we utilized a large RAD-seq dataset for white oaks (McVay et al., 2017b; Hipp et al., 2018) to develop a low-cost single-nucleotide polymorphism (SNP) genotyping kit for eastern North American white oaks (Fitzek et al., 2018). We demonstrated our 80-marker SNP kit to be effective at identifying 15 species and $\mathrm{F}_{1}$ hybrids and validated it in a garden setting, where we found hybridization between non-native species in the collection and the native white oaks of the surrounding woodlands.

\footnotetext{
1 The history of Gray's reports of hybrids is instructive. The first edition (Gray \& Sullivant, 1848) included two hybrids in the genus Quercus, each reported to be "founded on" a single tree or individual. In the 1857 through 1862 editions (Gray, 1857, 1859, 1862), this number increased to three, which Gray described as "the following remarkable forms, by some regarded as species." Gray's language changes between 1848 and 1862_years flanking the publication of Origin of Species—from suggesting that these hybrids are mere sports to suggesting that they might be species of hybrid origin. Gray was a great supporter of Darwin and had an avid correspondence with him even before publication of Origin (Browne, 2010), and Gray's change in language undoubtedly reflects a change in his view of the evolutionary implications of hybridization.
} 

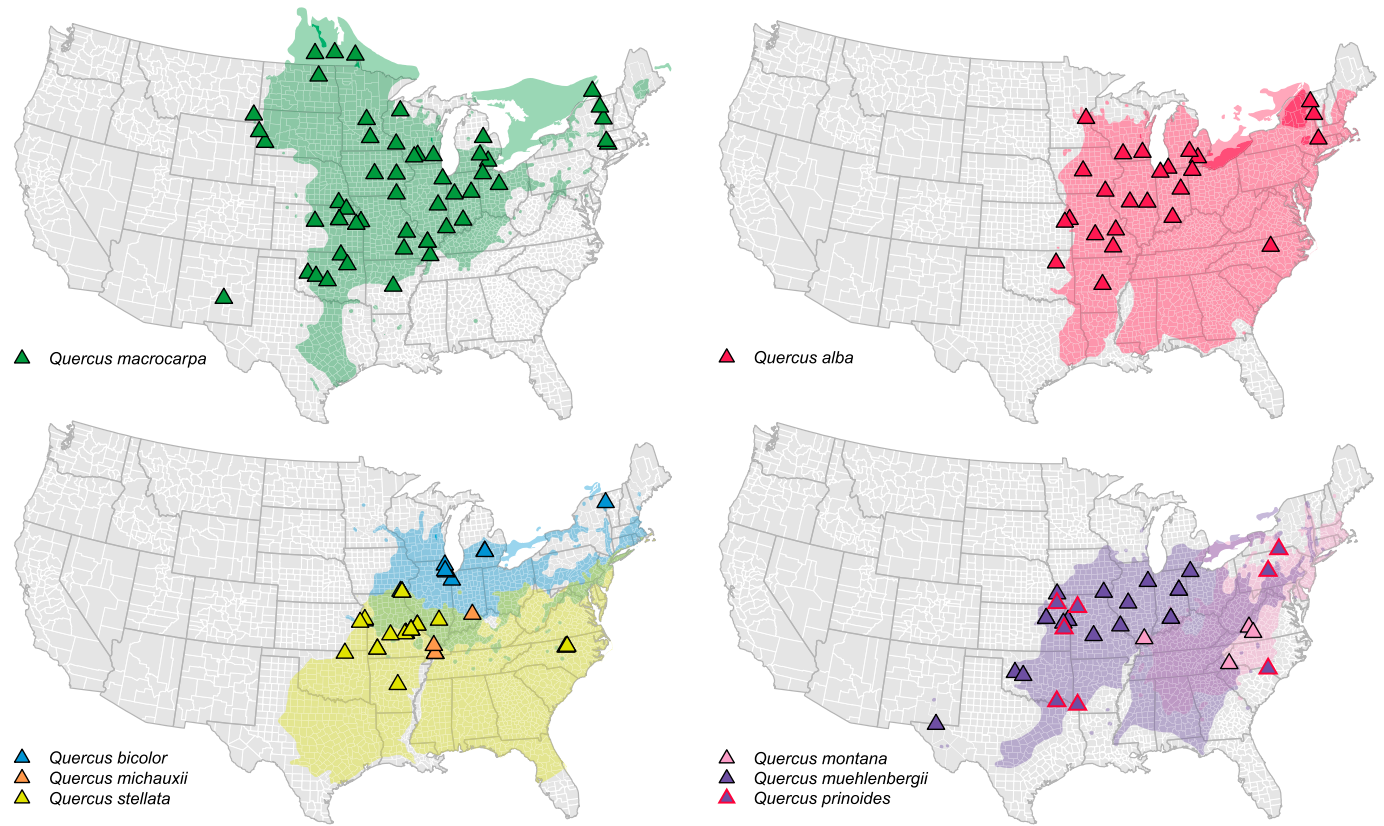

Figure 1. Sampling map. Sites were sampled to roughly cover the range of the taxa as known; on each panel, collections are overlaid on the range maps for each species following Little (1971, 1977, 1979), except for Quercus prinoides Willd., for which a base map was not available.

In the current study, we test this marker set in natural populations across a range-wide sample of seven eastern North American white oaks. These species are components of a classic syngameon, where there is good documentation of interspecific hybridization in many combinations (Hardin, 1975) and introgressive exchange of chloroplast haplotypes (Whittemore \& Schaal, 1991; Pham et al., 2017). We investigate whether the species are genetically cohesive at these 80 loci or a subset thereof, representing areas of the genome that have presumably been shielded from introgression across the range of the species. We also map these markers back to a chromosome-level assembly of the Quercus robur L. genome (Plomion et al., 2018) to investigate whether they are distributed across the genome or, conversely, whether genetic cohesion of the eastern North American white oaks is concentrated in a few genomic islands of differentiation. Our study provides a first framework investigation of the eastern North American white oak syngameon using a genome-wide sample of molecular markers, laying the groundwork for future studies of introgression and species cohesion in the group.

\section{Materials and Methods}

SAMPLING AND GENOTYPING

Data were initially collected from 184 individuals of seven eastern North American white oak species, encompassing a wide geographic range for each species.
In this study, Quercus muehlenbergii Engelm. and Q. prinoides Willd. are separated in name only, as our RAD-seq data failed to distinguish the species (McVay et al., 2017b; Hipp et al., 2018), and consequently no SNPs were identified to distinguish them from each other (Fitzek et al., 2018). The species status of these two bears investigation with broader sampling. Throughout the remainder of this paper, we will refer to these two together as Q. muehlenbergii/prinoides, not because we are making a claim that they are not distinct taxonomically, but to reinforce that they are grouped for analysis. Samples represent unique adults with seven exceptions, for which a second extraction of each individual was genotyped as a technical replicate. Individuals were selected to be typical of the species morphologically, not to be a random sample of all potential pure and introgressed individuals. Twentyone individuals for which fewer than $90 \%$ of loci amplified successfully were removed from analysis and are not discussed further in this paper, leaving a final set of 163 individuals analyzed (Fig. 1, Table 1).

To reduce the opportunity for hybridization with taxa from outside the natural range of each species, samples were preferentially selected from wild populations or from trees grown in gardens from seeds of known wild provenance (as discussed in Fitzek et al., 2018; Hipp et al., 2018); five individuals were analyzed from cultivated material (Table 1). Sample size per species ranges from seven to nine in Quercus montana Willd. 


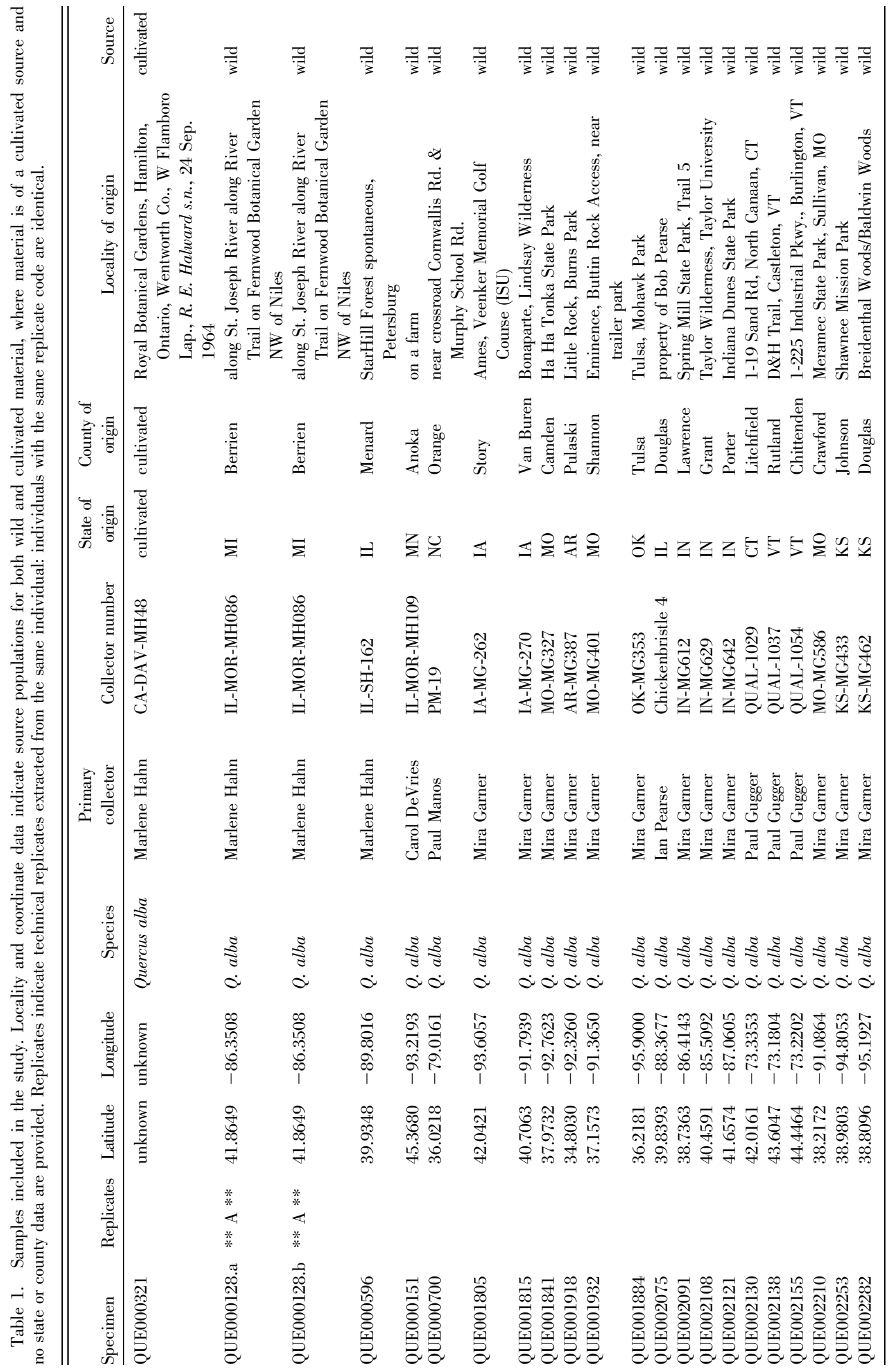




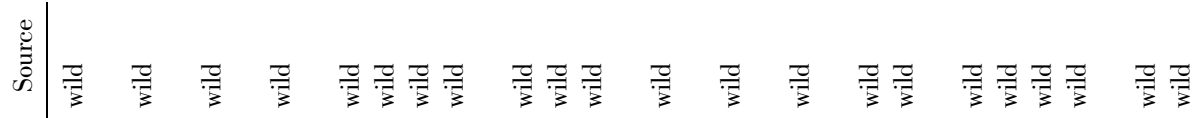

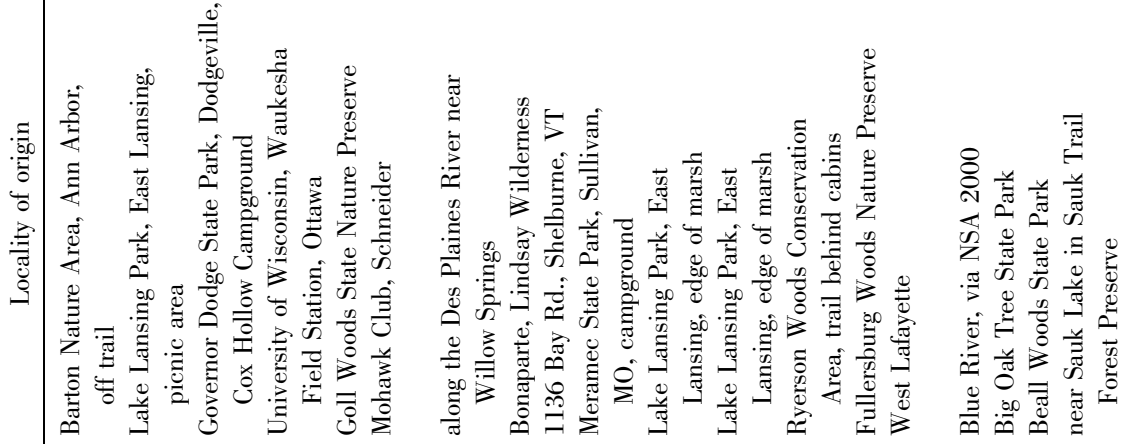

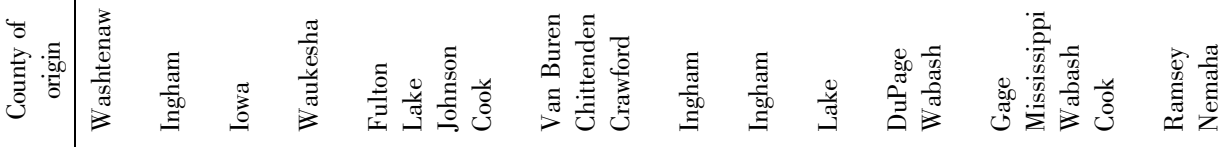

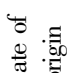

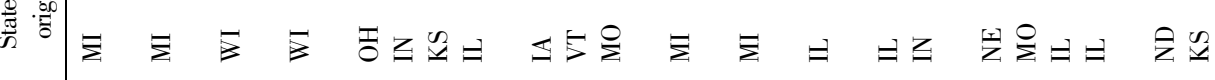

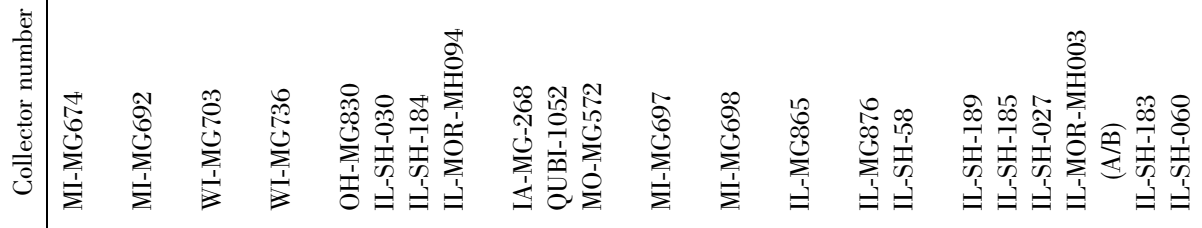

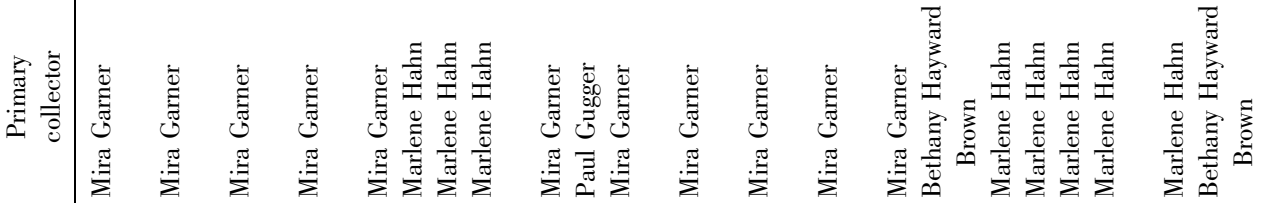

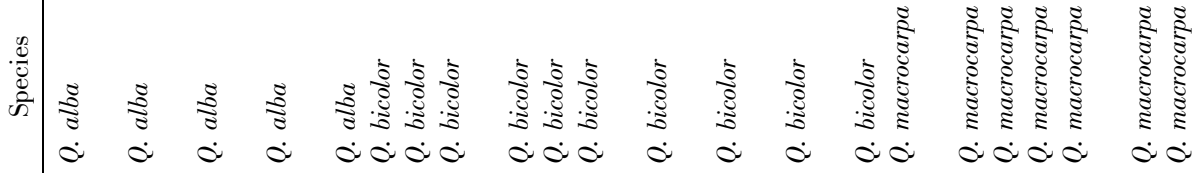

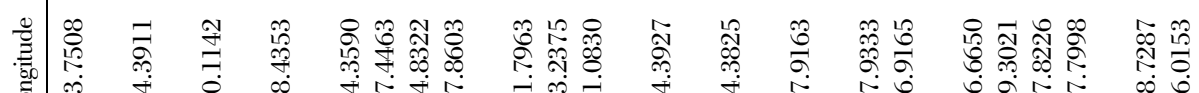

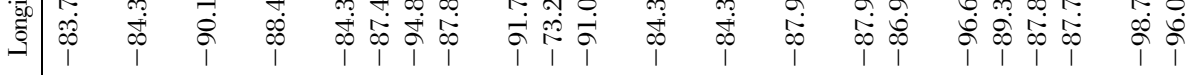

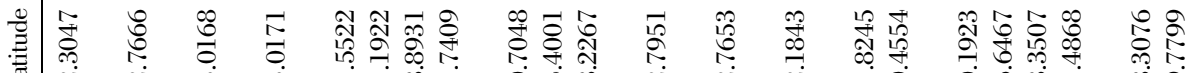

牙

ن.

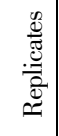

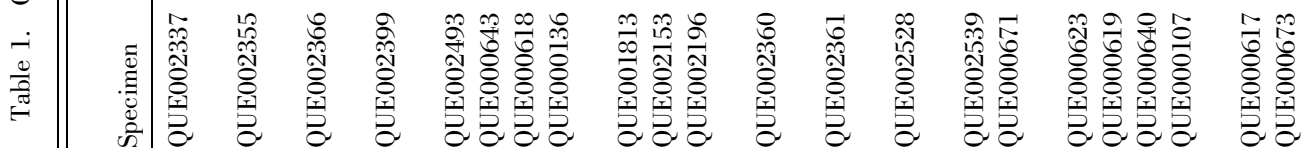




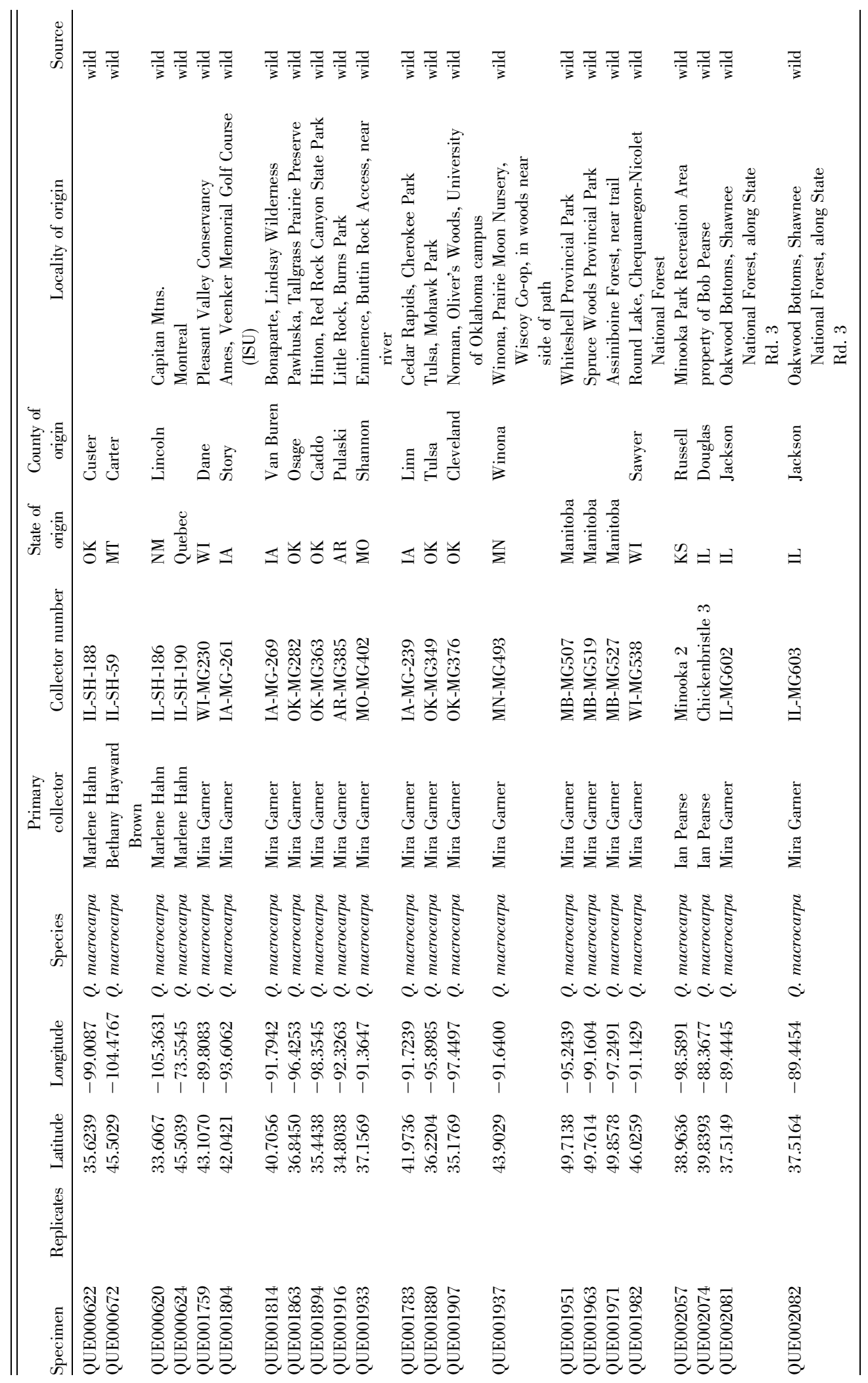




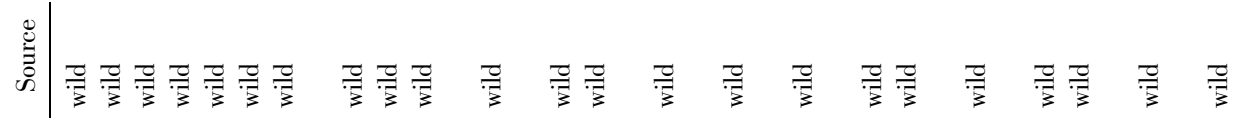

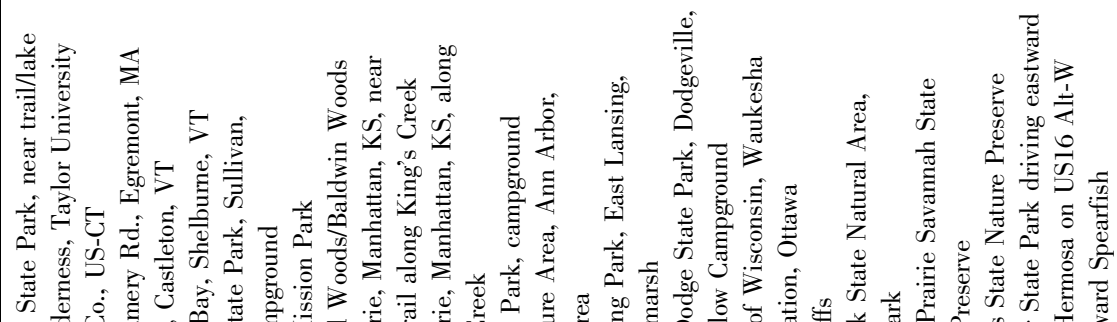

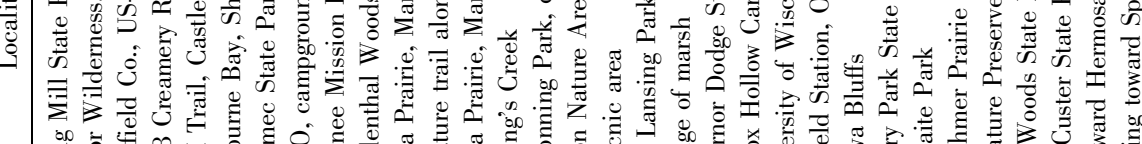

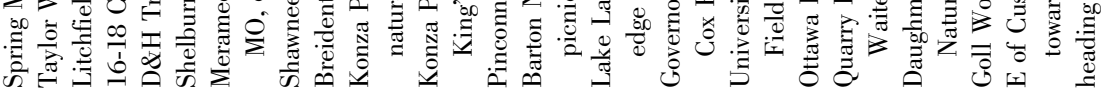

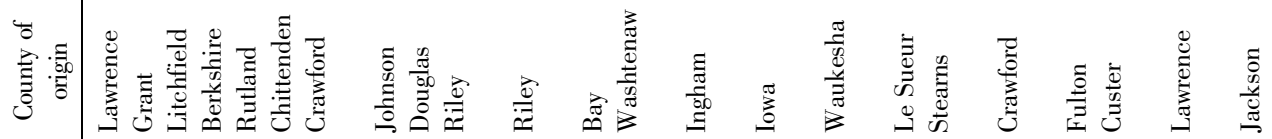
它 :

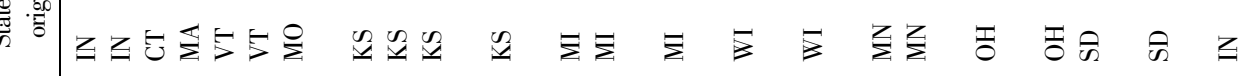

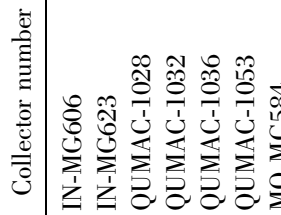

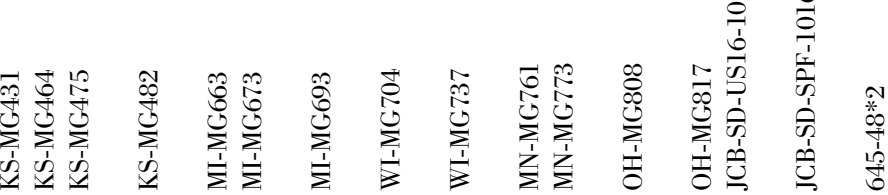

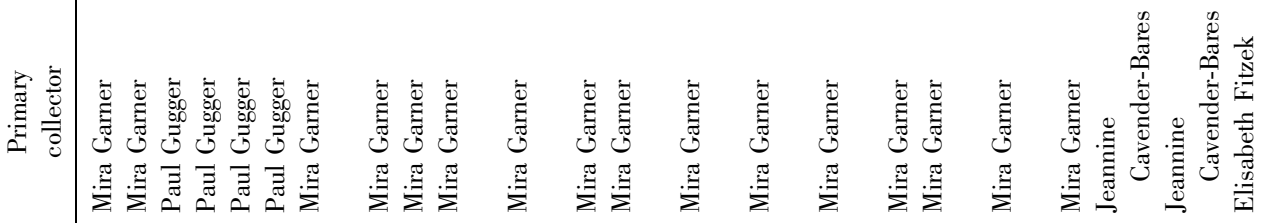

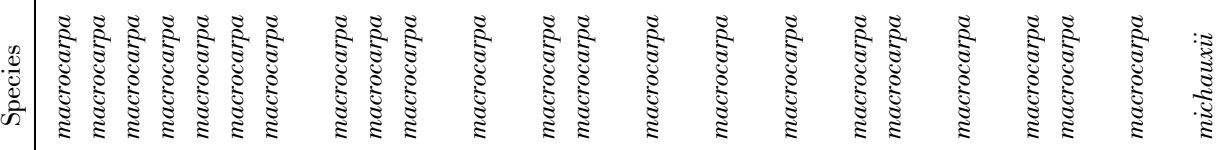
$\dot{\sigma} \dot{\alpha} \dot{\alpha} \dot{\alpha} \dot{\alpha} \dot{\alpha} \dot{\alpha} \dot{\alpha} \dot{\alpha} \dot{\alpha} \dot{\alpha} \dot{\alpha} \dot{\alpha} \dot{\alpha} \dot{\alpha} \dot{\alpha}$

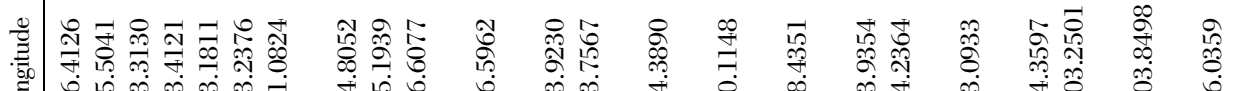

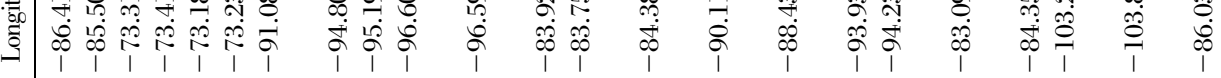

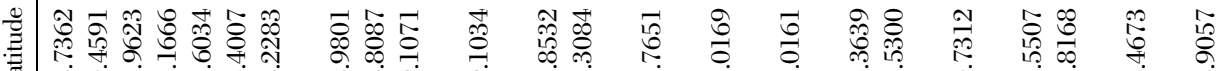
可

| 离 


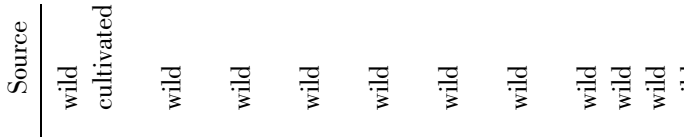

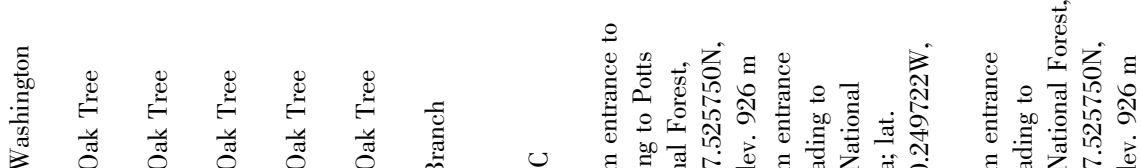

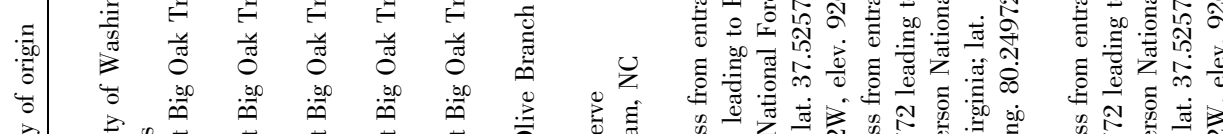

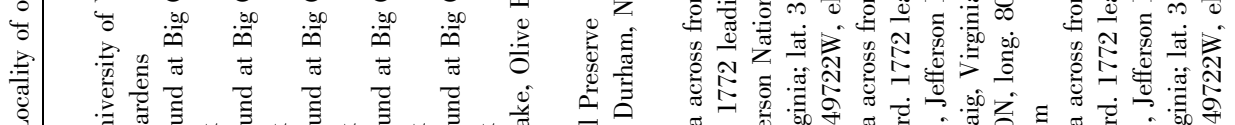

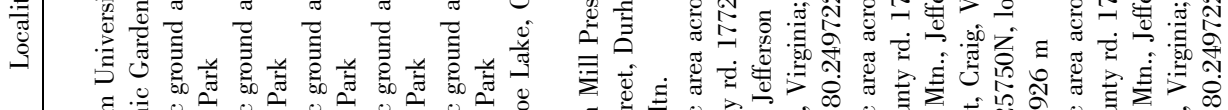

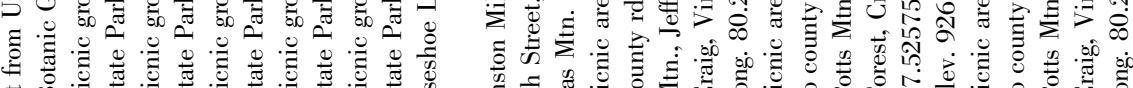

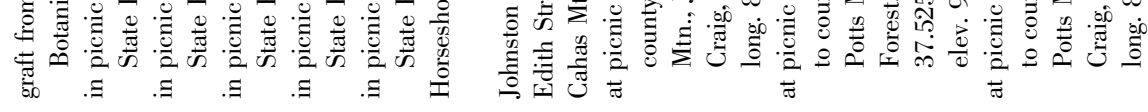

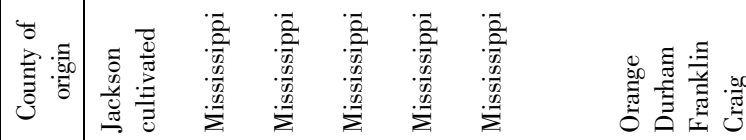

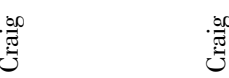

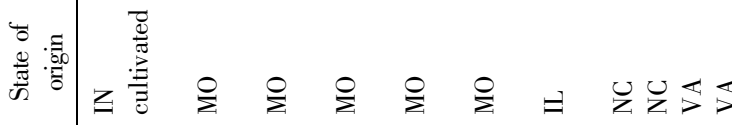

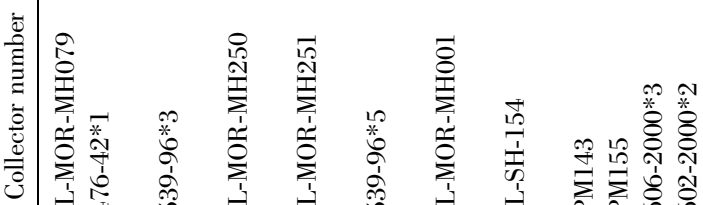

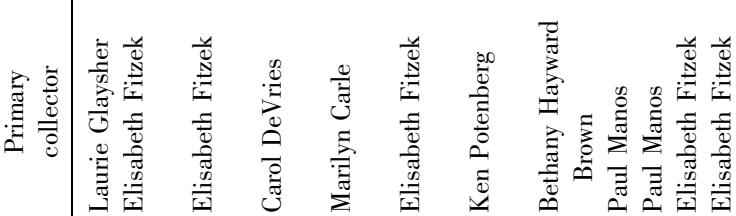

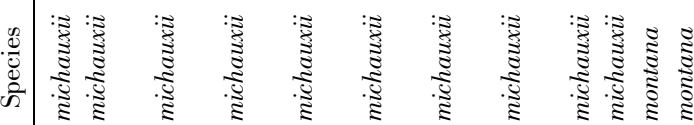

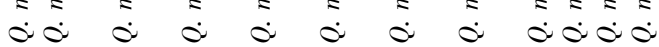

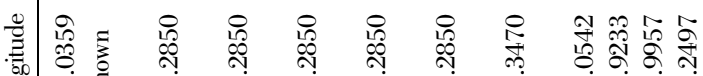

可

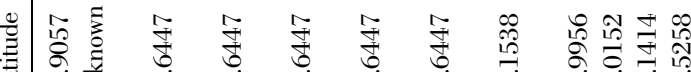

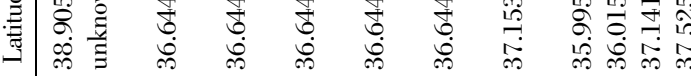

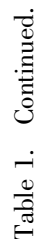

政

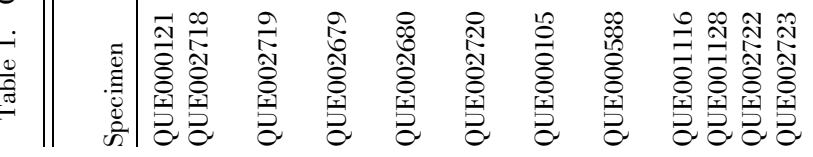

草草

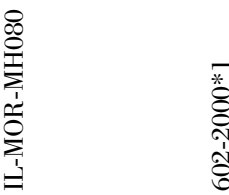

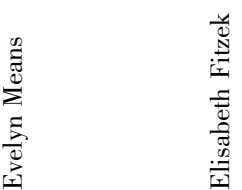

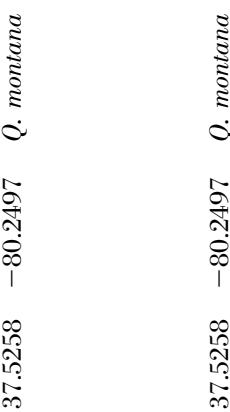

*

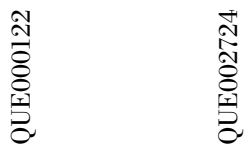




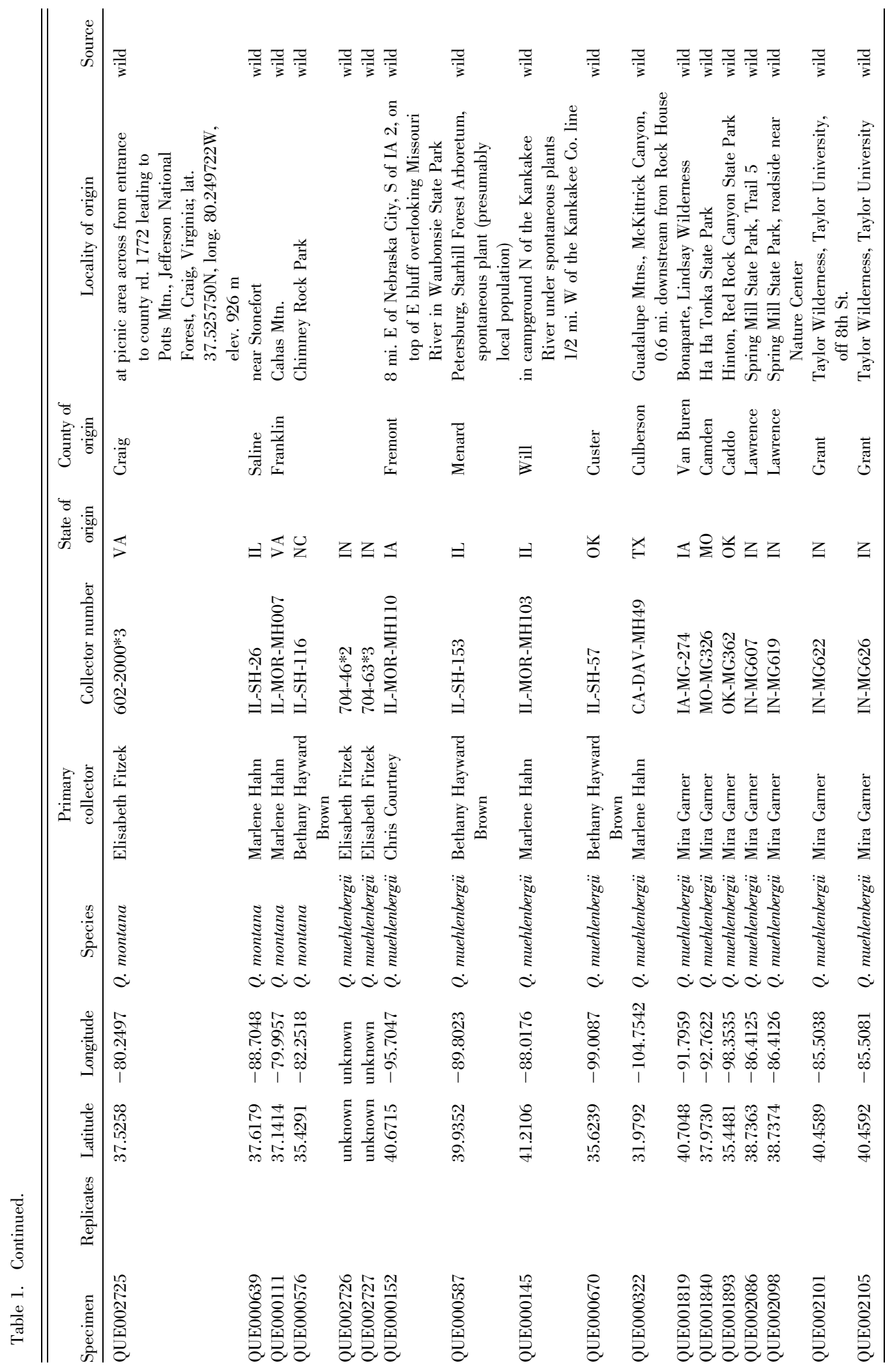




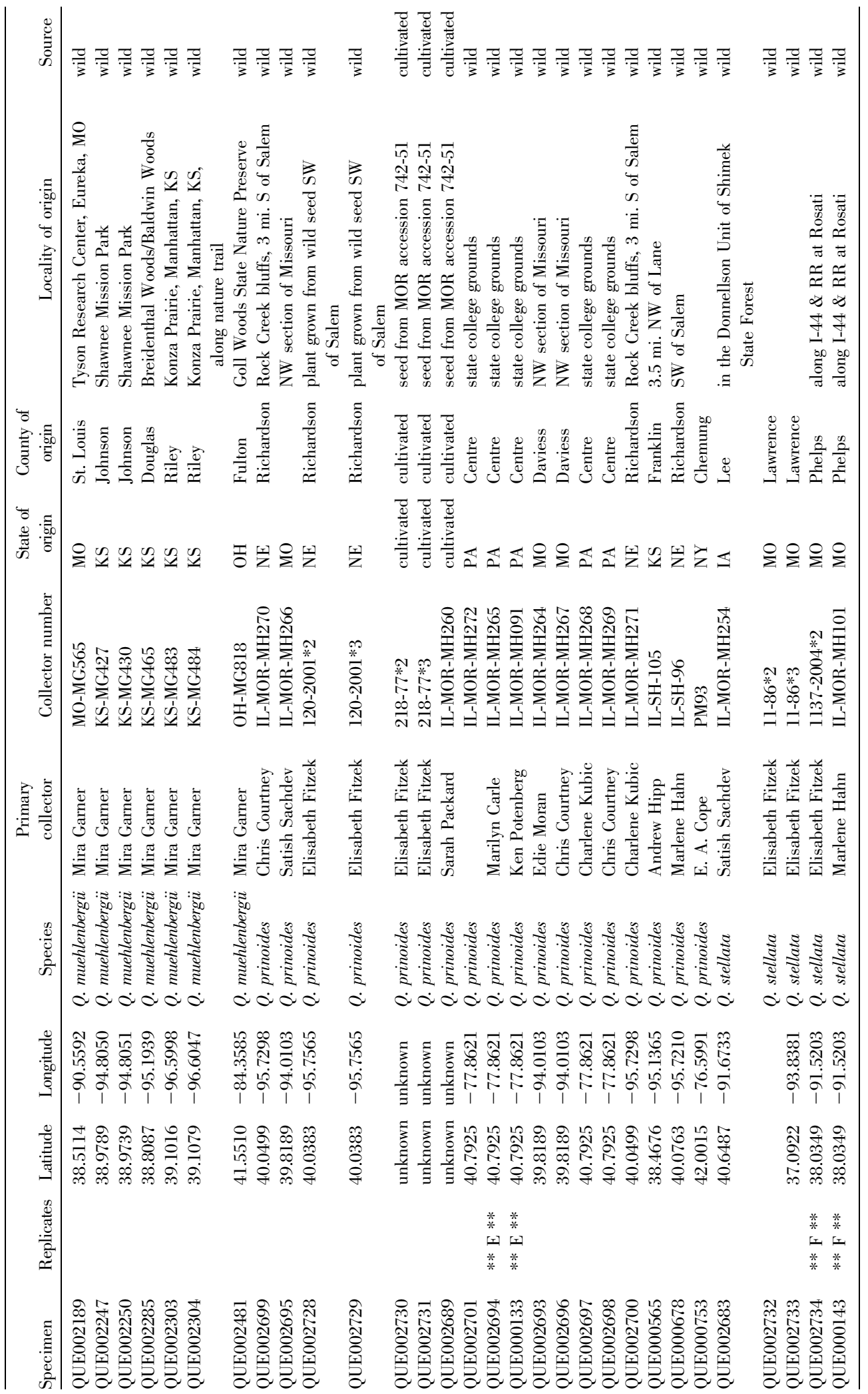




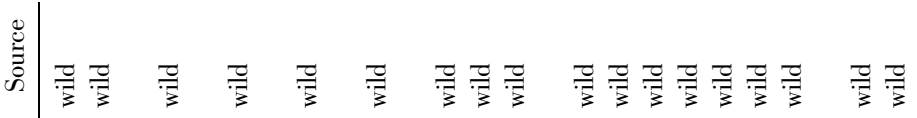

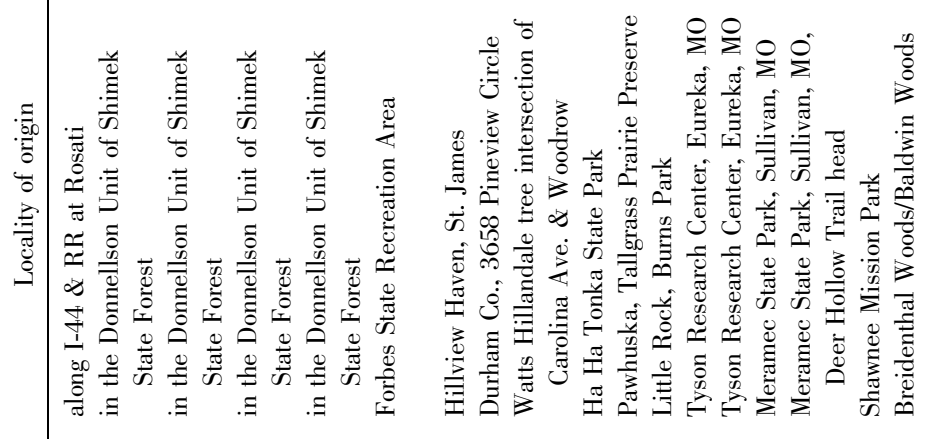

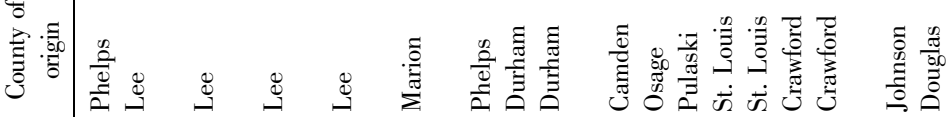
प्ठ

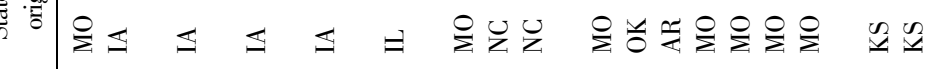

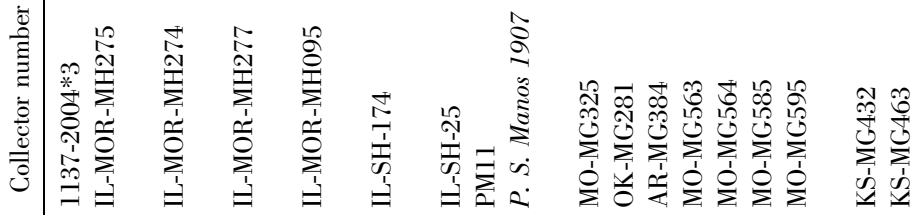

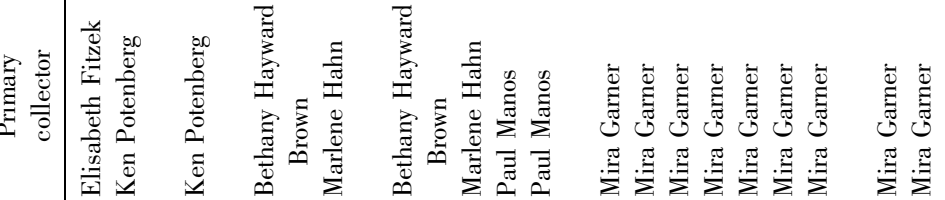

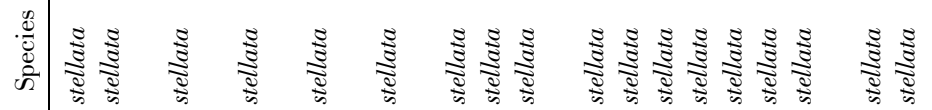
$\dot{\alpha} \dot{\alpha} \dot{\alpha} \dot{\alpha} \dot{\alpha} \dot{\alpha} \dot{\alpha} \dot{\alpha} \dot{\alpha} \dot{\alpha} \dot{\alpha}$

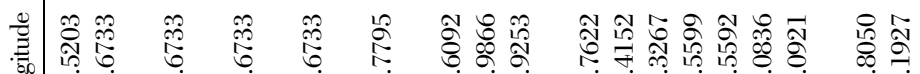

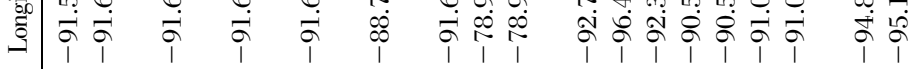

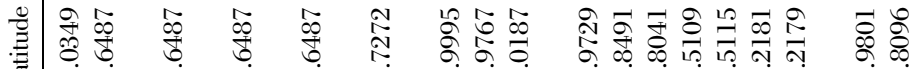
馬 
Table 2. Sample sizes, sample distances and ranges, and overall species ranges. Sample distance (D) maximum and median were calculated from Table 1 using the Haversine formula. Species ranges were inferred from range maps of Little (1971, 1977, 1979) for all species except Quercus prinoides Willd., which was estimated by visual inspection of maps published in Flora of North America (Nixon, 1997).

\begin{tabular}{lccccccc}
\hline \hline & & $\begin{array}{c}\text { Sample } \\
\text { D max }(\mathrm{km})\end{array}$ & $\begin{array}{c}\text { Sample } \\
\text { D median }(\mathrm{km})\end{array}$ & $\begin{array}{c}\text { Sample } \\
\text { latitude }\end{array}$ & $\begin{array}{c}\text { Species } \\
\text { latitude }\end{array}$ & Sample longitude & $\begin{array}{c}\text { Species } \\
\text { longitude }\end{array}$ \\
\hline Q. macrocarpa & 52 & 3005.3 & 888.8 & $33.6,49.9$ & $28,52.7$ & $-105.4,-73.2$ & $-104.4,-66.1$ \\
Q. alba & 26 & 2120.1 & 695 & $34.8,45.4$ & $29.6,46.5$ & $-95.9,-73.2$ & $-96.3,-69.1$ \\
Q. muehlenbergii & 21 & 2098.3 & 543 & $32,41.6$ & $24.8,44.7$ & $-104.8,-84.4$ & $-105.2,-72.2$ \\
Q. stellata & 21 & 1565.6 & 325.6 & $34.8,40.6$ & $27.6,41.8$ & $-96.4,-78.9$ & $-101.4,-70$ \\
Q. prinoides & 17 & 1618.9 & 185.9 & $38.5,42$ & $34.1,42.9$ & $-95.8,-76.6$ & $-99.8,-70$ \\
Q. bicolor & 10 & 1889.8 & 453.4 & $38.2,44.4$ & $35.2,46.4$ & $-94.8,-73.2$ & $-96.4,-70$ \\
Q. michauxii & 9 & 939 & 380.5 & $36,38.9$ & $28.8,41$ & $-89.3,-78.9$ & $-95.5,-74.3$ \\
Q. montana & 7 & 771.3 & 277.8 & $35.4,37.6$ & $32,44.6$ & $-88.7,-80$ & $-90,-70.5$ \\
\hline
\end{tabular}

and Q. michauxii Nutt. to 38 to 52 in Q. muehlenbergii/ prinoides and $Q$. macrocarpa Michx., respectively (Table 1). The distance between the most widely separated populations sampled within each species ranges from $771 \mathrm{~km}$ in Q. montana to $3005 \mathrm{~km}$ in Q. macrocarpa (Table 2). Moreover, aside from samples of $Q$. macrocarpa at the westernmost and northernmost edges of its range (Fig. 1), almost all samples in our study were collected from within the range of at least one other species. Consequently, while our study does not encompass the entire range of each species, the samples cover a wide geographic range within each species, with the opportunity for crossing among congeners. Locations for source populations of all samples for which source information was available were plotted over published range maps. Range maps were plotted from shapefiles (Prasad \& Iverson, 2003) generated from previously published range maps of North American trees (Little, 1971, 1977, 1979) over the "county" and "state" base maps provided in maps v. 3.3.0 (Becker et al., 2018) for R v. 3.4.2, "Short Summer" (R-DevelopmentCore-Team, 2004). All plotting was done in R using the ggplot2 (Wickham, 2009) and ggmap (Kahle \& Wickham, 2013) packages, using proj4 (Urbanek, 2012) for map projections.

Samples were genotyped using an 80-SNP DNA toolkit developed to distinguish 15 eastern North American white oaks (as described in Fitzek et al., 2018). Briefly, an extensive RAD-seq dataset comprising multiple exemplars of all 15 species (McVay et al., 2017b) was surveyed for SNP variation, using pairwise $\mathrm{F}_{\mathrm{ST}}$ to identify SNPs that were (1) fixed or nearly fixed between species and (2) flanked by at least $20 \mathrm{bp}$ of conserved sequence, which could be used for primer design. Multiplexes of up to 40 primers for potential SNPs were designed using the Assay Design 4.0 Suite (Agena Biosciences, San Diego, California, U.S.A.), which is optimized for MassARRAY analysis (Bradić et al., 2012). Samples were genotyped using the iPLEX Gold chemistry following Gabriel et al. (2009) on a MassARRAY system (Agena Biosciences) at the Genomic Platform of Bordeaux with the help of Adline Delcamp. Data analysis was completed using MassARRAY Typer Analyzer 4.0.26.75 (Agena Biosciences). We manually checked each marker clustering to detect potential ambiguous genotype assignation or unusable SNP. The results were exported as a genotype table for downstream analyses. After genotyping, five SNPs were removed from analysis because they failed to amplify in more than $30 \%$ of individuals.

The oak genome was not yet available when this DNA toolkit was published, but since then a chromosomelevel genome has been published for Quercus robur (Plomion et al., 2018), a white oak closely related to the species for which this toolkit was developed. To evaluate the genomic independence of the loci we used in this study, all RAD-seq loci used to develop the $80 \mathrm{SNPs}$ were mapped to the oak genome using BLASTN (Altschul et al., 1990; Camacho et al., 2009) with a threshold EValue of 0.0001. Each RAD-seq locus was identified as mapping to a single position on a chromosome, multiple positions, or not mapping. All SNPs were designed from distinct RAD-seq loci save two (CL_2457_66 and CL_2457_32), which both come from a single RAD-seq locus that maps to position $36,055,433$ on $Q$. robur chromosome 12 . The two SNPs identified in this locus were designed to distinguish $Q$. stellata from the remaining taxa and should not be considered independent of one another. They are not strongly decisive and do not figure prominently in downstream analyses in this study or in Fitzek et al. (2018).

Genomic clustering of loci was evaluated by calculating intervals between loci on each chromosome and comparing these to a simulated null distribution. The null distribution was simulated based on 10,000 replicate datasets of 59 loci drawn at random from the 41,898 uniquely mapped PstI RAD-seq loci from the larger study from which our SNPs were developed (Hipp 
et al., 2019). Three test statistics were evaluated: mean interval length between all loci on all chromosomes; number of intervals $<1 \mathrm{E} 04 \mathrm{bp}$; and number of intervals $<1$ E06 bp. Code for performing this test is archived in $<$ https://github.com/andrew-hipp/whiteoak-syngameon $>$.

\section{DATA ANALYSIS: EVALUATING SPECIES COHESION}

We define species cohesion operationally in this study using two criteria: (1) clustering of all plants sampled from each species in genetic space, exclusive of other species, and irrespective of geography; and (2) minimal evidence of genetic admixture between species at some conserved region of the genome (in this case, based on preselected markers). By this definition, clustering of individuals by geography instead of by species would be evidence against species cohesion, as would sharing of alleles between individuals of different species, when those alleles are nearly fixed between the species. This operational definition corresponds with practices widely used by plant systematists to define "good species" (Rieseberg et al., 2006) as well as statistical methods traditionally used to infer patterns and degree of interspecific introgression (Anderson, 1949). It puts off for the time being possible empirical and philosophical issues with cohesion species as a concept (Barker, 2007; Barker \& Wilson, 2010) as well as questions about the mechanisms by which species cohere (Morjan \& Rieseberg, 2004).

We assess criterion 1, clustering in genetic space, using the unweighted pair group method with arithmetic mean (UPGMA) (Sokal \& Michener, 1958), a clustering method that aggregates individuals based on a pairwise distance matrix, in this case a Euclidean distance matrix based on allele counts within individuals, where each allele is present as 0,1 , or 2 copies per individual. UPGMA is well suited to within-species comparisons of genetic data or other comparisons of data that are truly ultrametric, where it performs reasonably well as an estimator of genetic relatedness (Felsenstein, 2004). In our study, UPGMA has the desirable property of apportioning genetic variance to branches, so that we can assess whether the variance in our data is better assigned to among-species or within-species differences. Because our markers are designed with extreme bias toward among-species differences, we do not attempt to quantify variance components using analysis of molecular variance (AMOVA) (Excoffier et al., 1992) and urge that the clustering results not be interpreted as estimating these variance components. We compare UPGMA results with non-metric multidimensional scaling (NMDS) ordination on the same data matrix. We present results from the three-dimensional ordination because it suffices to discriminate the species in our study.
We assess criterion 2 using the Bayesian population genetic clustering algorithm implemented in STRUCTURE v 2.3.4 (Pritchard et al., 2000). We utilized the admixture model with correlated allele frequencies and $\lambda$ fixed at 1.0, allowing $K$ (the number of populations) to range from 1 to 12 . For each value of $K$, we ran 10 replicate Markov chain Monte Carlo (MCMC) runs of 1 E06 generations following a 1E05 generation burn-in. We followed the method of Evanno et al. (2005) to identify the most probable value of $K$ based on the maximum value of $\Delta K$, but given the problematic nature of identifying $K$ with hierarchical data, we report the configurations recovered under multiple values of $K$. We utilized STRUCTURE HARVESTER (<http:// taylor0.biology.ucla.edu/structureHarvester/ $>$ ) (Earl \& vonHoldt, 2012) to calculate the Evanno statistics and CLUMPP v 1.1.2 for 64-bit Linux (Jakobsson \& Rosenberg, 2007) to average STRUCTURE run replicates for each value of $K$. We visualized results using DISTRUCT v. 1.1 (Rosenberg, 2004).

To evaluate whether the entire SNP toolkit is necessary to discriminate among the species we are studying and to identify SNPs that might be fixed within species, we calculated the absolute number and proportion of individuals within each species possessing each polymorphism observed. With the caveat that sampling is uneven across species (ranging from $\mathrm{N}=7$ in Quercus montana to $\mathrm{N}=52$ in Q. macrocarpa), the resulting heatmap (Fig. 2, Supplementary Figure S1) and the table underlying it (Supplementary Table S1) estimate the decisiveness of each SNP relative to species identification in this species group: the summed proportion of individuals by species that have a given SNP estimates that SNP's decisiveness, where a sum of 1.0 or 2.0 (for Q. muehlenbergii/prinoides) indicates a locus that is alone decisive for a taxon for the samples we have genotyped. The reduced set may have practical benefit for both cost and because the combinability of primer pairs plays a crucial role in multiplexing (Fitzek et al., 2018). Decisiveness was overlaid on the mapped SNPs to identify whether loci that are fixed or nearly fixed within species are genomically clustered (Table 3 ).

All data and code required to reproduce analyses presented here are archived in <https:/github.com/ andrew-hipp/white-oak-syngameon $>$.

\section{REsults}

In the full dataset of 184 individuals for 80 loci, missing data per individual averaged $2.56 \pm 4.10 \%$ (SD) loci, and missing data per locus averaged $14.6 \pm$ $26.8 \%$ (SD) individuals. In the dataset cleaned to 163 individuals for 75 loci, excluding individuals with $>10 \%$ missing loci and loci with $>30 \%$ missing individuals, missing data dropped to $1.19 \pm 1.13 \%$ 


\title{
Quercus macrocarpa
}

\author{
Quercus alba
}

\section{Quercus muehlenbergii}

\author{
Quercus stellata
}

\section{Quercus prinoides}

\author{
Quercus bicolor
}

\section{Quercus michauxii}

\section{Quercus montana}

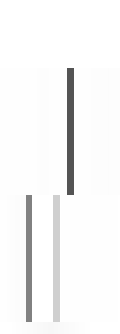

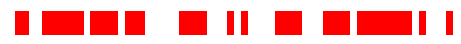
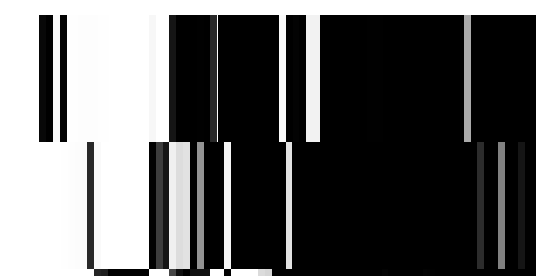

Figure 2. Single-nucleotide polymorphism (SNP) heatmap by species. Darkness of cells indicates the percent of individuals of a given named species possessing the indicated nucleotide. Red bars along the top of the figure indicate SNPs in 20 loci that we hand-selected because they were highly decisive for the species represented in the present study. Names of all loci are included in Supplementary Figure S1.

missing loci per individual and $5.60 \pm 13.9 \%$ missing individuals per locus. Of the 75 cleaned loci, 20 were monomorphic and 55 had two or more polymorphisms. Among seven pairs of technical replicates, a total of 38 differences were found. Of these, 37 were differences in whether a locus amplified or not; only one difference in allele call was found (for locus CL_55087_OAKMOR340_32, G/T in Quercus stellata QUE002706 vs. G/G in specimen QUE000137). Thus, among $7 \times$ $75=525$ replicated sites, only one genotyping error $(0.17 \%)$ and 37 loci that failed to amplify in one of the two replicates $(6.43 \%)$ were detected.

Seven loci exhibit only a single SNP for exactly one species in our dataset-one in Quercus alba L., two in Q. michauxii, four in Q. montana - and three exhibit a single SNP in Q. muehlenbergii/prinoides. An additional 10 SNPs exhibit a summed proportion between 0.95 and 1.05, suggesting relatively high decisiveness for $Q$. stellata (two SNPs) and Q. bicolor (three SNPs). Based on these, we handpicked 20 SNPs that suffice to diagnose the species in our study (Fig. 2, Supplementary Figure S1, red bars).
Using all loci, the UPGMA (Fig. 3, Supplementary Figure S2) and NMDS ordination (Fig. 4) both clearly separate individuals by species, except for Quercus prinoides and Q. muehlenbergii, which our SNP genotyping primers were not designed to distinguish from one another. Thus there are seven distinct clusters recognized in this study. Individuals of these clusters separate with no overlap in three-dimensional genetic ordination space (Fig. 4; note that while some species overlap in one or two dimensions, none overlap in all three) and UPGMA stem lengths that equal or exceed the species crown depth for four of the clusters $(Q$. macrocarpa, Q. bicolor, Q. muehlenbergii/prinoides, and Q. montana) and, for the other three, stem lengths that are approximately equal to $(Q$. stellata, $Q$. michauxii) or substantially less than $(Q$. alba $)$ the crown height. Using the 20 handpicked loci, our SNP genotyping toolkit successfully distinguishes species from one another using UPGMA (Fig. 3, Supplementary Figure S2).

Bayesian admixture analysis in STRUCTURE favors a $K=4$ solution using the $\Delta K$ statistic of Evanno et al. (2005). Given the susceptibility of STRUCTURE and 
Table 3. Map positions and decisiveness of singlenucleotide polymorphisms (SNPs) that map to a unique position on one of the Quercus robur L. chromosomes. The 60 SNPs that map back to one of the 12 Q. robur chromosomes inferred in Plomion et al. (2018) are shown here with their start position on the $Q$. robur chromosome to which they map and their decisiveness. Shading changes from top to bottom of the table indicate different oak chromosomes. All loci mapped with identity $>95 \%$, locus length $>70 \mathrm{bp}$, and E-value $<1.0 \times$ $10^{-30}$. The table demonstrates that the most decisive loci in our toolkit are distributed across all chromosomes except 5,7 , and 11 , and separated by an average of 7.47 million bp \pm 8.74 million bp (SD). Five pairs of loci are $<10,000 \mathrm{bp}$ from one another-loci at positions LG2, 2.72E07; LG2, 5.65E07; LG3, 2.99E07; and LG12, 2.11E07, two pairs of loci-and bear further investigation as potentially falling within genomic islands of differentiation. Mapping details from BLASTN and mapping information from non-uniquely mapping loci and loci that did map are in Supplemental Table S3.

\begin{tabular}{llllc}
\hline \hline Query (locus) & $L G$ & Start (bp) & Dist. (bp) & Decisiveness \\
\hline locus_11631_48 & 01 & $1.32 \mathrm{E}+07$ & & \\
locus_17927_52 & 01 & $1.92 \mathrm{E}+07$ & $6.04 \mathrm{E}+06$ & $*$ \\
newl_21880_27 & 01 & $2.02 \mathrm{E}+07$ & $9.71 \mathrm{E}+05$ & $* * *$ \\
locus_821_26 & 01 & $4.61 \mathrm{E}+07$ & $2.59 \mathrm{E}+07$ & \\
newl_17339_35 & 01 & $4.85 \mathrm{E}+07$ & $2.40 \mathrm{E}+06$ & $* *$ \\
CL_42027_ & 02 & $9.97 \mathrm{E}+06$ & & $* *$ \\
CL_6426_61 & 02 & $1.46 \mathrm{E}+07$ & $4.62 \mathrm{E}+06$ & \\
locus_4492_52 & 02 & $2.38 \mathrm{E}+07$ & $9.21 \mathrm{E}+06$ & \\
locus_20180_49 & 02 & $2.72 \mathrm{E}+07$ & $3.37 \mathrm{E}+06$ & \\
locus_3962_56 & 02 & $2.72 \mathrm{E}+07$ & $1.90 \mathrm{E}+03$ & \\
CL_49075_43 & 02 & $4.71 \mathrm{E}+07$ & $1.99 \mathrm{E}+07$ & \\
CL_35240 & 02 & $5.65 \mathrm{E}+07$ & $9.40 \mathrm{E}+06$ & $* *$ \\
locus_12538_49 & 02 & $5.65 \mathrm{E}+07$ & $9.16 \mathrm{E}+03$ & $* * *$ \\
locus_23517_52 & 02 & $6.66 \mathrm{E}+07$ & $1.01 \mathrm{E}+07$ & \\
new1_23554_ & 02 & $7.19 \mathrm{E}+07$ & $5.26 \mathrm{E}+06$ & \\
locus_3169_44 & 02 & $7.55 \mathrm{E}+07$ & $3.68 \mathrm{E}+06$ & \\
locus_9121_49 & 02 & $9.24 \mathrm{E}+07$ & $1.68 \mathrm{E}+07$ & \\
CL_55087_32 & 02 & $9.38 \mathrm{E}+07$ & $1.43 \mathrm{E}+06$ & $*$ \\
locus_8059_35 & 03 & $2.99 \mathrm{E}+07$ & & $*$ \\
CL_11069_58 & 03 & $2.99 \mathrm{E}+07$ & $2.65 \mathrm{E}+03$ & $*$ \\
locus_8717_53 & 03 & $3.81 \mathrm{E}+07$ & $8.25 \mathrm{E}+06$ & \\
locus_7123_50 & 03 & $4.03 \mathrm{E}+07$ & $2.18 \mathrm{E}+06$ & $* *$ \\
locus_5882_32 & 03 & $5.25 \mathrm{E}+07$ & $1.22 \mathrm{E}+07$ & \\
locus_8617_30 & 04 & $3.15 \mathrm{E}+07$ & & $* *$ \\
locus_5229_56 & 05 & $5.16 \mathrm{E}+07$ & & $* *$ \\
locus_29214_32 & 06 & $1.28 \mathrm{E}+07$ & & $* *$ \\
locus_10977_45 & 06 & $2.04 \mathrm{E}+07$ & $7.58 \mathrm{E}+06$ & \\
CL_54979_ & 06 & $3.53 \mathrm{E}+07$ & $1.49 \mathrm{E}+07$ & \\
CL_12923_ & 06 & $4.47 \mathrm{E}+07$ & $9.42 \mathrm{E}+06$ & $* *$ \\
locus_7834_43 & 06 & $4.58 \mathrm{E}+07$ & $1.02 \mathrm{E}+06$ & $* *$ \\
newl_27648_32 & 07 & $1.25 \mathrm{E}+07$ & & \\
locus_5482_34 & 07 & $2.57 \mathrm{E}+07$ & $1.32 \mathrm{E}+07$ & \\
locus_27412_25 & 07 & $3.67 \mathrm{E}+07$ & $1.10 \mathrm{E}+07$ & \\
locus_30948_43 & 08 & $9.66 \mathrm{E}+05$ & & \\
locus_5422_58 & 08 & $4.43 \mathrm{E}+07$ & $4.34 \mathrm{E}+07$ & \\
locus_26761_43 & 08 & $5.11 \mathrm{E}+07$ & $6.78 \mathrm{E}+06$ & $* * *$ \\
locus_24383_42 & 08 & $6.07 \mathrm{E}+07$ & $9.62 \mathrm{E}+06$ & \\
locus_10104_41 & 08 & $6.92 \mathrm{E}+07$ & $8.51 \mathrm{E}+06$ & $* *$ \\
locus_28457_43 & 09 & $1.90 \mathrm{E}+07$ & & \\
newl_16979_31 & 09 & $2.81 \mathrm{E}+07$ & $9.05 \mathrm{E}+06$ & \\
\hline & & & & \\
\hline
\end{tabular}

Table 3. Continued.

\begin{tabular}{lcccc}
\hline \hline \multicolumn{1}{c}{ Query (locus) } & $L G$ & Start (bp) & Dist. (bp) & Decisiveness \\
\hline locus_1378_30 & 09 & $3.61 \mathrm{E}+07$ & $8.08 \mathrm{E}+06$ & $* * *$ \\
locus_30512_25 & 10 & $2.75 \mathrm{E}+06$ & & $* *$ \\
locus_2085_53 & 10 & $3.57 \mathrm{E}+07$ & $3.29 \mathrm{E}+07$ & \\
locus_20667_37 & 11 & $2.92 \mathrm{E}+07$ & & \\
locus_14289_31 & 11 & $3.02 \mathrm{E}+07$ & $9.02 \mathrm{E}+06$ & \\
CL_48165 & 12 & $1.46 \mathrm{E}+07$ & & $* * *$ \\
locus_11302_50 & 12 & $1.61 \mathrm{E}+07$ & $1.55 \mathrm{E}+06$ & $* *$ \\
locus_31722_39 & 12 & $1.75 \mathrm{E}+07$ & $1.34 \mathrm{E}+06$ & $* * *$ \\
locus_9837_55 & 12 & $2.05 \mathrm{E}+07$ & $3.04 \mathrm{E}+06$ & \\
newl_25158_45 & 12 & $2.11 \mathrm{E}+07$ & $5.67 \mathrm{E}+05$ & \\
locus_26885_29 & 12 & $2.11 \mathrm{E}+07$ & $3.37 \mathrm{E}+03$ & $* * *$ \\
locus_792_52 & 12 & $2.11 \mathrm{E}+07$ & $5.29 \mathrm{E}+04$ & \\
locus_8226_51 & 12 & $2.11 \mathrm{E}+07$ & $7.99 \mathrm{E}+03$ & $* * *$ \\
locus_25236_45 & 12 & $2.12 \mathrm{E}+07$ & $9.02 \mathrm{E}+04$ & $* *$ \\
newl_15918_ & 12 & $2.41 \mathrm{E}+07$ & $2.83 \mathrm{E}+06$ & \\
PM11_41 & & & & \\
locus_10802_36 & 12 & $2.99 \mathrm{E}+07$ & $5.81 \mathrm{E}+06$ & \\
locus_17368_30 & 12 & $3.54 \mathrm{E}+07$ & $5.49 \mathrm{E}+06$ & \\
CL_2457_32 & 12 & $3.61 \mathrm{E}+07$ & $6.97 \mathrm{E}+05$ & \\
CL_2457_OAK- & 12 & $3.61 \mathrm{E}+07$ & & same locus \\
M0R-340_66 & & & & \\
locus_4850_29 & 12 & $3.92 \mathrm{E}+07$ & $3.12 \mathrm{E}+06$ & \\
& & &
\end{tabular}

Abbreviations: Decisiveness, decisiveness of the SNP for identifying one species or a pair of species (cf. Fig. 2); Dist. (bp), distance in base pairs from the start of the locus to the end of the locus adjacent to it on the same chromosome; LG, linkage group (chromosome number), following Plomion et al. (2018); Query (locus), the RAD-seq locus SNP abbreviation from Fitzek et al. (2018); Start (bp), start position of the RAD-seq locus on the $Q$. robur chromosome.

*Within 0.200 of 1.000 or 2.000 .

$* *$ Within 0.100 of 1.000 or 2.000 .

***An SNP whose decisiveness is exactly 1.000 or 2.000 for the sample studied here (i.e., diagnostic for one or two species).

particularly the $\Delta K$ statistic to the highest hierarchical level of genetic structure in a dataset, we find the $K=4$ solution not a useful description of genetic structure in our phylogenetically structured dataset. To the contrary, the $K=4$ clustering does the best job at separating species by clade, following well-supported phylogenetic relationships (Hipp et al., 2018), viz. four clusters comprising Quercus macrocarpa and Q. bicolor; Q. alba, Q. michauxii, and Q. montana; and Q. stellata and $Q$. muehlenbergii/prinoides each on their own (Fig. 5). Given our phylogenetically structured sample, it is not surprising that $\Delta K$ favors a configuration that splits individuals among clades above the species level. STRUCTURE continues to distinguish species up until $K=8$, with seven species pairs yielding individuals admixed $10 \%$ or more based on our markers (Figs. 5, 6). Notably, it is not until $K=8$ that the seven species are distinguished from each other, perhaps due to high genetic variation within species that is not adequately 


\section{A. UPGMA, 75 loci}

- Quercus alba

- Quercus bicolor

- Quercus macrocarpa

- Quercus michauxil

- Quercus montana

- Quercus muehlenbergii

- Quercus prinoides

- Quercus stellata

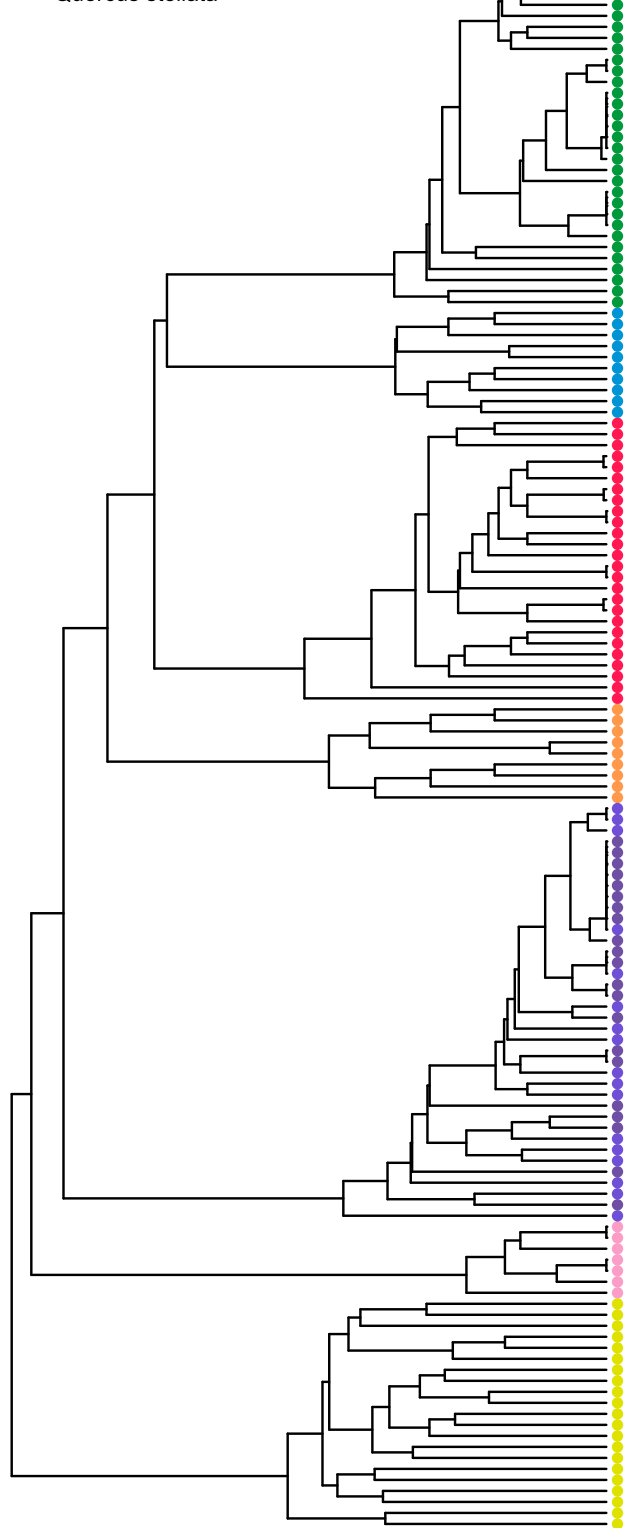

B. UPGMA, 20 loci

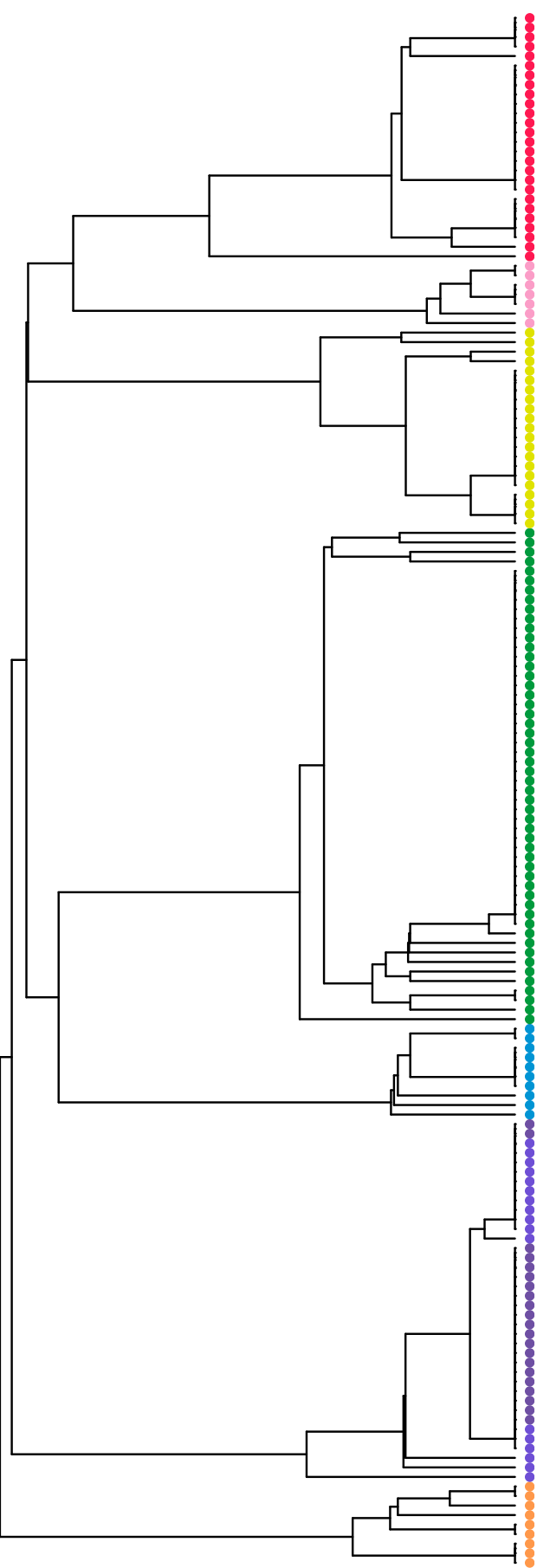

Figure 3. Unweighted pair group method with arithmetic mean (UPGMA), all loci (A) and 20 loci (B). UPGMA was conducted on a Euclidean distance matrix calculated from a three-state nucleotide matrix, where each nucleotide present for each SNP is coded as $0=$ absent, $1=1$ copy (i.e., individual is heterozygous for that single-nucleotide polymorphism [SNP]), $2=2$ copies (i.e., individual is homozygous for that SNP). (A) UPGMA clustering based on all 75 loci. (B) UPGMA clustering based on 20 loci hand-selected for their decisiveness in the species sample represented here (cf. Fig. 2, red bars). Full sample names are included in Supplemental Figure S2. 

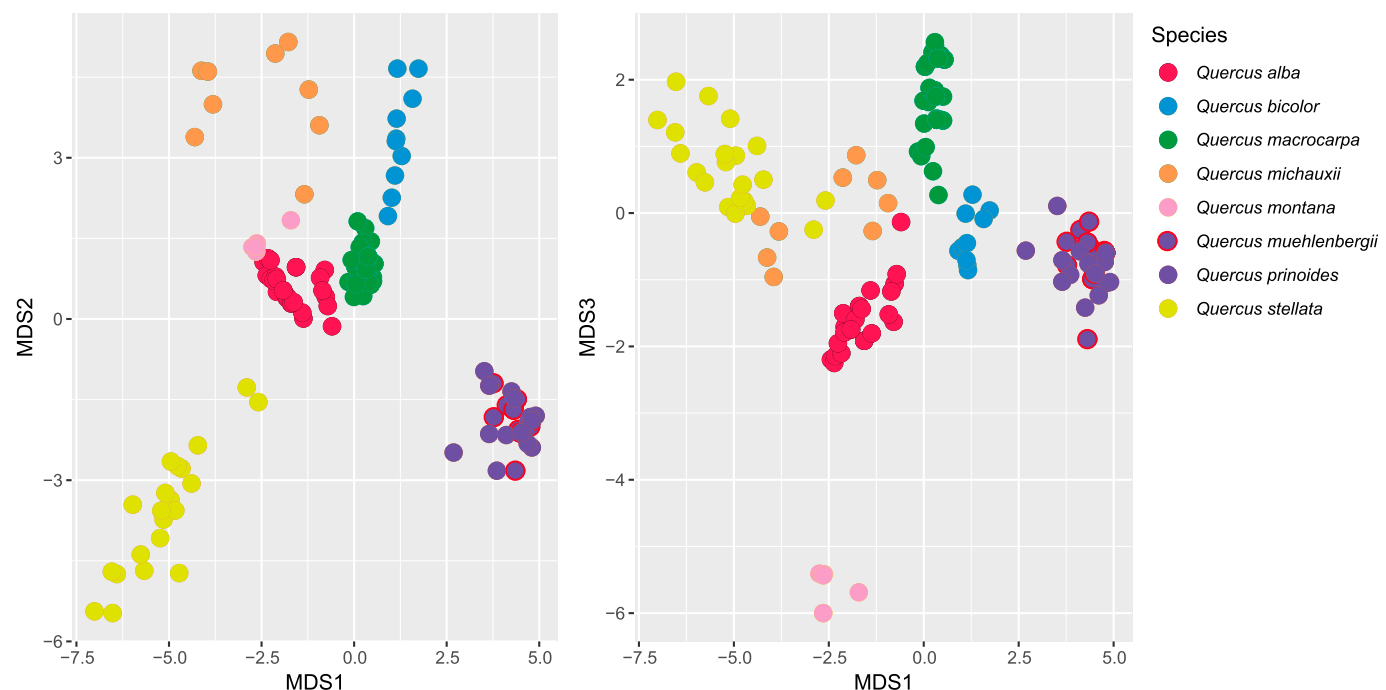

Figure 4. Non-metric multidimensional scaling (NMDS) ordination, 75 loci. NMDS was conducted in three dimensions for the same Euclidean distance matrix used in Figure 3. NMDS ordination final stress was 0.08607 and failed to reach convergent solutions in 20 iterations, but all replicate ordination attempts distinguished all pairs of species in at least one dimension, as seen in this figure.

resolved with these markers. One individual identified as Q. alba in the field shows evidence of introgression from both $Q$. macrocarpa and $Q$. bicolor. In the $K=8$ configuration, Q. bicolor gives the appearance of being uniformly admixed with $Q$. montana at a relatively low level (9/10 individuals $<10 \%$ admixed). However, this appears to be artifactual, as the phenomenon is absent in the $K=6,7$, and 9 configurations, all of which show genetic separation between $Q$. bicolor and $Q$. montana. In the $K=8$ configuration, $Q$. alba resolves as a mix of two genotypes, which we combine in estimating the number of individuals admixed at $5 \%, 10 \%, 15 \%$, or $20 \%$ (Supplementary Table S2, Fig. 6).

Of the 79 RAD-seq loci used to design our SNP toolkit-79 rather than 80 because two of our SNPs derive from a single locus- 59 map to a unique position on one chromosome (hereafter referred to as "uniquely mapped loci"), nine map to multiple locations in the genome, and 11 do not map to any location in the genome (Table 3, Supplementary Table S3). The uniquely mapped loci demonstrate that decisiveness is spread across the genome: 25 loci diagnostic for one or two species are found on nine out of the 12 Quercus chromosomes (Table 3). Moreover, distances between loci within chromosomes are mostly $>1$ million bp (37/47 interlocus distances), and only $11 \%$ (5/47 interlocus distances) are $<10,000 \mathrm{bp}$. Distances between uniquely mapped loci average 7.47 million bp ( \pm 8.74 million bp, $\mathrm{SD})$. These are all significantly clustered relative to a random draw of SNPs, under which only 0.909 interlocus distances $<10,000$ bp are expected $(P<0.0001), 4.70$ interlocus distances $<1,000,000 \mathrm{bp}(P=0.0123)$, and mean interlocus distance is expected to be $9.440 \times 10^{6}$ $(P<0.0001)$. Only two of the 11 RAD-seq loci that did not map to the genome exhibit moderate decisiveness (0.81-0.869, where 1.0 or 2.0 indicates loci that are perfectly decisive for one or two species, respectively). Three of the nine loci that map to multiple locations are highly decisive (1.000-1.021).

\section{Discussion}

Our study demonstrates that with a relatively small amount of curated data-just 20 SNPs chosen to maximize genetic distinctiveness-we are able to distinguish seven genetically cohesive taxa. The fact that we are able to identify fixed or nearly fixed SNPs across wide geographic ranges in several species suggests that introgression is distributed heterogeneously along the genome, with some areas of the genome strongly protected against introgression on a species-pair by species-pair basis. Given that several of the apparently fixed SNPs are limited to our species with smallest sample size-one in Quercus bicolor $(\mathrm{N}=10)$, two in Q. michauxii $(\mathrm{N}=9)$, four in Q. montana $(\mathrm{N}=7)$ - the question of whether they are truly fixed bears further investigation. However, $Q$. muehlenbergii/prinoides is represented by 38 individuals in our dataset and three fixed SNPs, suggesting that the high-frequency proportional representation of SNPs in some species may not be an artifact of low sample size. We interpret this finding as evidence that these seven species are genetically cohesive across their ranges at least at a small number of regions of the genome, even in the face of introgression. 


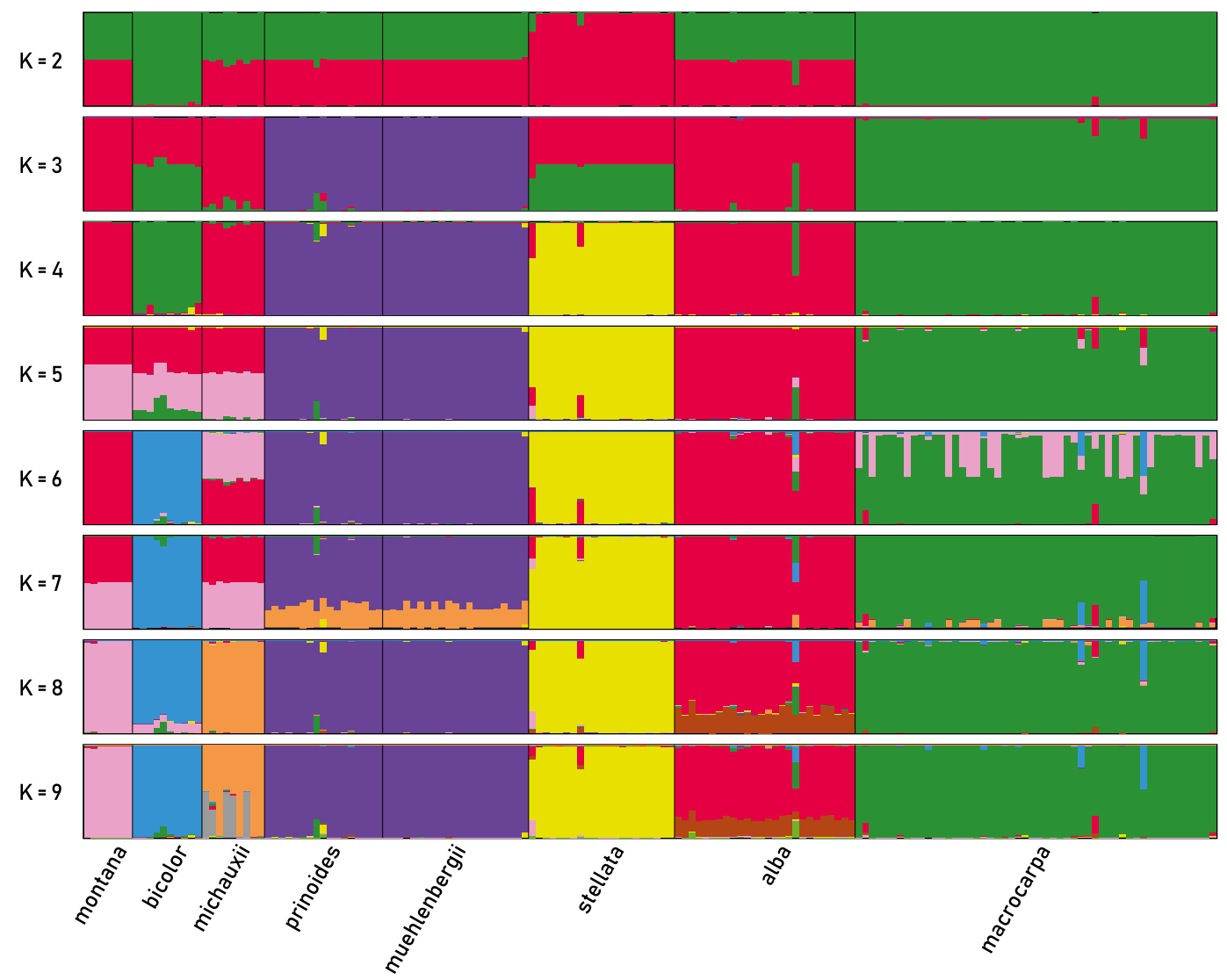

Figure 5. Bayesian admixture analysis conducted in STRUCTURE, assuming $K=2$ to $K=9$ populations. STRUCTURE analyses were conducted under the admixture model with correlated allele frequencies, from $K=1$ to $K=12$. Values of $K$ above 9 provide no additional information on population structure and are consequently not shown here. All figures represent averages over 10 independent runs of 1E06 generations each following 1 E05 burn-in generations; runs were aggregated for display using the "greedy" algorithm in CLUMPP.

It is somewhat remarkable that we are able to distinguish seven interbreeding oak species with just 20 handpicked markers. By comparison, the now-classic study demonstrating genetic distinctiveness of Quercus petraea (Matt.) Liebl. and Q. robur L. utilized 20 microsatellites for just those two species (Muir et al., 2000). Other studies using five (Craft \& Ashley, 2006), six (Moran et al., 2012), or even 15 variable microsatellites (Aldrich et al., 2003) have by contrast failed to find consistent genetic differentiation between two to three co-occurring white or red oaks (for a counter example of relatively clean differentiation based on only 11 microsatellites, see Cavender-Bares \& Pahlich, 2009). All used markers selected for variability rather than for segregation by species. Larger numbers of loci (as low as 27 to 28 in, e.g., Owusu et al., 2015; Sullivan et al., 2016) tend to pick up divergent neutral markers or markers under divergent selection (Lind-Riehl et al., 2014b; Sullivan et al., 2016). This suggests that a moderate-sized but random sample of loci will often reflect regions of the genome that either are not yet differentiated between species (Muir \& Schlötterer, 2005,2006 ) or are subject to ancient or contemporary gene flow (Lexer et al., 2006). Because the loci that bear the stamp of population divergence history for one species pair may record introgression history for other species pairs (Crowl et al., 2019; Hipp et al., 2019), we would not expect any particular small set of loci to adequately describe species description across the oak phylogeny. In the current study, however, we have demonstrated that a small number can suffice to distinguish numerous species in a multispecies syngameon.

The SNPs we have utilized may be linked to loci under strong selection. They may as a consequence not be representative of the genome as a whole. As discussed in the paper in which these SNPs were published (Fitzek et al., 2018), we selected SNPs by querying a RAD-seq dataset for loci that had pairwise $\mathrm{F}_{\mathrm{ST}}>0.95$. Such outlier loci can tell much more refined stories about population divergence than loci that are not under 


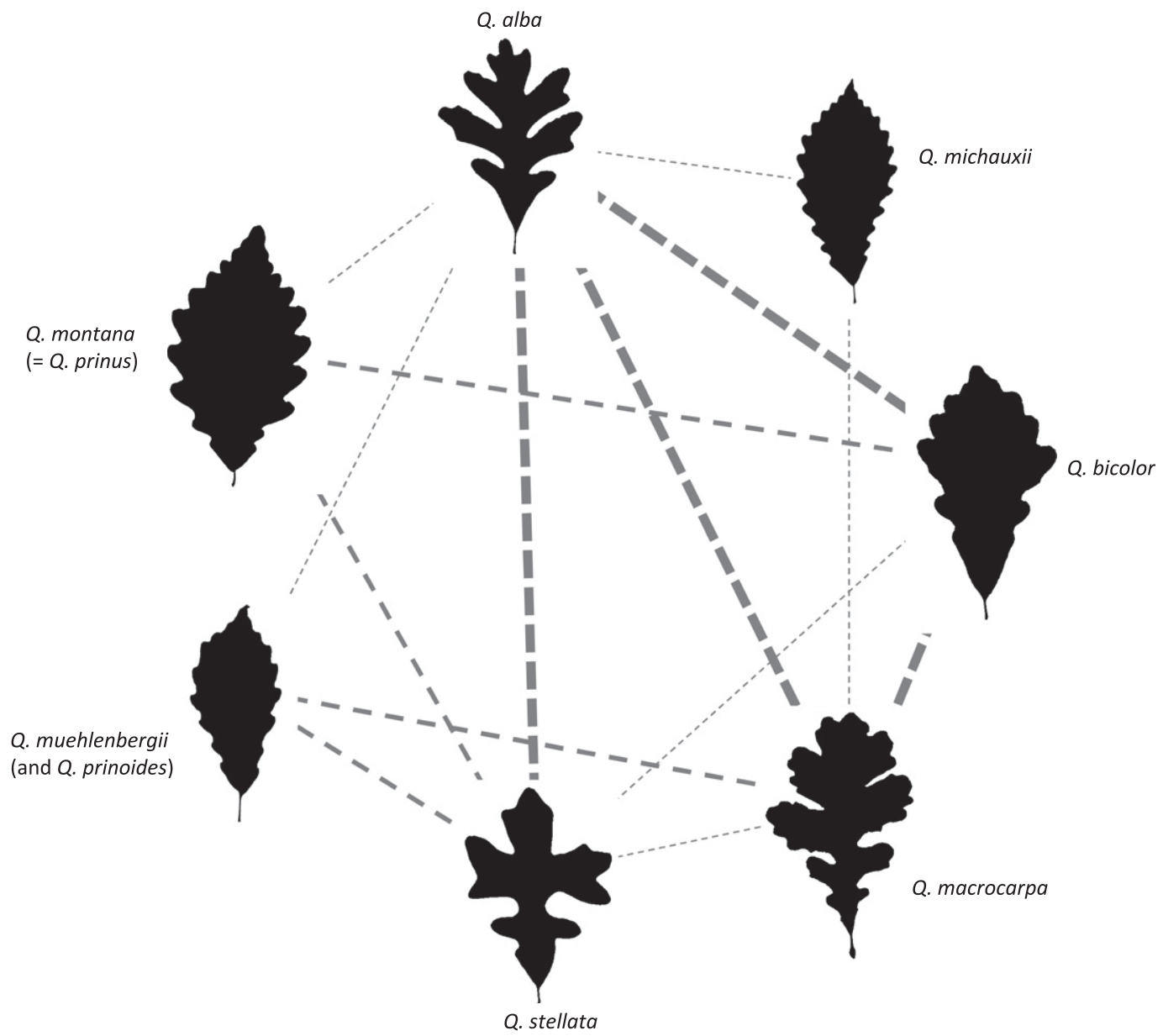

Figure 6. The white oak syngameon of eastern North America sensu Hardin (1975), including only the species investigated in the current study. The figure replicates the 16-species figure of Hardin (1975: fig. 1), including only the subset of seven species we investigated in the current study (treating Quercus muehlenbergii Engelm. and Q. prinoides Willd. as one), with lines indicating hybridizations that Hardin inferred from morphological study. Thin-dashed lines indicate hybridizations identified by Hardin but not by us; medium-dashed lines were identified by both Hardin and us, at an admixture level of 0.10 to 0.19 for at least one specimen; and thick-dashed lines indicate admixture levels of 0.20 or higher for at least one specimen. Vouchers for leaf silhouettes are Q. alba L.: P. S. Manos 1838 (MOR 177669); Q. michauxii Nutt.: P. S. Manos 1843 (MOR 177659); Q. bicolor Willd.: P. S. Manos 1847 (MOR 177662); Q. macrocarpa: IL-MOR-MH108 (MOR 174544); Q. stellata Wagenh.: P. S. Manos 1835 (MOR 177663); Q. muehlenbergii: PM-98; Q. montana Willd.: P. S. Manos 1860 (MOR 177731).

such strong selection (Scotti-Saintagne et al., 2004; Guichoux et al., 2013; Lind-Riehl et al., 2014b) and may thus pick up on divergence histories that are not clear from a broader sample of loci. These selected genes may occur in islands of differentiation distributed across the genome (Scotti-Saintagne et al., 2004; Goicoechea et al., 2015) and have the potential to explain genetic cohesion across species ranges even when populations diverge at neutral loci (Morjan \& Rieseberg, 2004) or to distinguish species that are exchanging genes more frequently across the remainder of the genome (Gailing \& Curtu, 2014; Lind-Riehl et al., 2014; Oney-Birol et al., 2018; Hipp, 2018). This gives them practical utility as a species identification toolkit. A genome-scale investigation, as has been conducted in the European white oaks (Leroy et al., 2017, 2018), would be required to characterize the genomic architecture of differentiation among these species and address the question of whether species differences are concentrated in divergent loci under strong selection. For the time being, our study suggests that a relatively small number of selected genes may suffice to diagnose-not define-species, even in the face of ongoing introgression.

Despite the low sampling of loci in our study, we do find significant clustering on the genome of loci within 1 
Mbp of each other $(P=0.008)$ or within $10 \mathrm{Kbp}$ of each other $(P<0.001)$. This supports earlier studies that have found significant clustering of high- $\mathrm{F}_{\mathrm{ST}}$ loci (ScottiSaintagne et al., 2004) as well as linkage disequilibrium (LD) among loci separated by as much as 20 centimorgans (cM) (Goicoechea et al., 2015). While the PstI RAD-seq loci used to design these SNPs are widespread on the genome, they are not randomly distributed, but rather are situated at higher-than-expected frequency within coding genes (Hipp et al., 2019). However, our simulated distribution accounts for this, as it is drawn from the larger RAD-seq dataset from which our SNPs were developed. Thus the clustering of our SNPs appears to reflect genomic clustering of outlier loci that distinguish species of the eastern North American white oak syngameon. The causes, consequences, and scale of these genomic islands of differentiation among eastern North American white oaks bear investigation using higher sampling of individuals and loci.

We expect our power to detect complex patterns of introgression in a multispecies hybrid zone to be compromised by the low locus sampling of this SNP toolkit. Nonetheless, our study demonstrates that even without attempting to find hybrids, potentially biasing ourselves against detecting introgression, and even without using the large numbers of loci generally favored for hybridization studies, we are able to identify introgressants involving several pairs of species from a sampling of natural populations (Figs. 5, 6). The fact that we have selected loci to be fixed or nearly fixed within species may aid in detecting first-generation hybrids. At the same time, by selecting genes with high pairwise $\mathrm{F}_{\mathrm{ST}}$, we effectively designed our SNPs within outlier loci (by definition, loci with higher-than-expected $\mathrm{F}_{\mathrm{ST}}$ ), which may overestimate divergence between species and underestimate the proportion of the genome that is subject to introgression. The pairs that we found to be admixed at the $10 \%$ level for at least one individual were also found by Hardin to hybridize (Fig. 6; cf. fig. 1 in Hardin, 1975). It remains to be seen using genomic markers that are not subject to the ascertainment bias in our study what the actual frequency and average percent of admixture are for these species.

\section{Conclusions}

Oaks have been a bugbear of evolutionary biology since Darwin's time, raising significant questions about what species are and how we can make sense of speciation in the face of ongoing gene flow (Arnold, 2016). Our work builds on studies that, in aggregate, suggest that oak species are genetically coherent across their ranges (Muir et al., 2000; Hipp \& Weber, 2008; Cavender-Bares \& Pahlich, 2009; Hauser et al., 2017) despite a history of introgression (Eaton et al., 2015;
McVay et al., 2017a; Kim et al., 2018). We concur with Hardin (1975: 360), who wrote, "Neither Baranski (1975) nor I agree with Minckler (1965), who thinks that hybridization may mask evidence of races within white oak."

Our study does not, however, speak to the frequency of hybridization, because our markers are selected for fixation or near-fixation within species. This bias may afford the markers increased utility to identify earlygeneration hybrids but make them poor estimators of genome-wide rates of genetic exchange. It is important to note, in fact, that we could have told the story of introgression with a different handpicked set of 20 or 80 SNPs: different regions of the genome-i.e., regions that reflect either gene flow or population divergence history more strongly - will suggest different histories of speciation and introgression. Both histories are embedded in the genome, and both are equally real. We cannot consequently assess Muller's (1952: 148) claim that "the bulk of claims of hybridity [in Quercus] are based upon trivial variations of the sort one may encounter in a relatively pure population of a single species." What we can say is that the eastern North American white oak syngameon is composed of entities that most taxonomists would consider "good species."

It is equally important to note that while our study demonstrates that there exist loci that distinguish species in the white oak syngameon across their ranges, it leaves open the question of which regions of the genome are responsible for species cohesion in oaks. As increasing evidence suggests that forest tree syngameons may be common, especially in the tropics (Cannon \& Lerdau, 2015; Caron et al., 2019; Kenzo et al., 2019), the forces shaping how and the degree to which different regions of the genome capture different aspects of population divergence and gene flow history will be a central question-perhaps the central question-of tree biodiversity for the coming decade.

\section{Literature Cited}

Aldrich, P. R., G. R. Parker, C. H. Michler \& J. RomeroSeverson. 2003. Whole-tree silvic identifications and the microsatellite genetic structure of a red oak species complex in an Indiana old-growth forest. Canad. J. Forest Res. 33: 2228-2237.

Allard, H. A. 1932. A progeny study of the so-called oak species Quercus saulii, with notes on other probable hybrids found in or near the District of Columbia. Bull. Torrey Bot. Club 59: 267-277.

Altschul, S. F., W. Gish, W. Miller, E. W. Myers \& D. J. Lipman. 1990. Basic local alignment search tool. J. Molec. Biol. 215: 403-410.

Anderson, E. 1949. Introgressive Hybridization. John Wiley $\&$ Sons, Inc., New York.

Arnold, M. L. 2016. Divergence with Genetic Exchange. Oxford University Press, Oxford. 
Baranski, M. J. 1975. An Analysis of Variation within White Oak (Quercus alba L.). North Carolina Agricultural Experiment Station, Raleigh.

Barker, M. J. 2007. The empirical inadequacy of species cohesion by gene flow. Philos. Sci. 74: 654-665.

Barker, M. J. \& R. A. Wilson. 2010. Cohesion, gene flow, and the nature of species. J. Philos. 107: 61-79.

Becker, R. A., A. R. Wilks, R. Brownrigg, T. P. Minka \& A. Deckmyn. 2018. maps: Draw Geographical Maps, version 3.3.0. $<$ https://CRAN.R-project.org/package $=$ maps $>$, accessed 13 August 2019.

Belahbib, N., M. H. Pemonge, A. Ouassou, H. Sbay, A. Kremer \& R. J. Petit. 2001. Frequent cytoplasmic exchanges between oak species that are not closely related: Quercus suber and Q. ilex in Morocco. Molec. Ecol. 10: 2003-2012.

Bradić, M., J. Costa \& I. M. Chelo. 2012. Genotyping with Sequenom. Pp. 193-210 in V. Orgogozo \& M. V. Rockman (editors), Molecular Methods for Evolutionary Genetics. Humana Press, Totowa, New Jersey.

Browne, J. 2010. Asa Gray and Charles Darwin: Corresponding naturalists. Harvard Pap. Bot. 15: 209-220.

Burger, W. C. 1975. The species concept in Quercus. Taxon 24: $45-50$.

Camacho, C., G. Coulouris, V. Avagyan, N. Ma, J. Papadopoulos, K. Bealer \& T. L. Madden. 2009. BLAST+: Architecture and applications. BMC Bioinformatics 10: 421.

Cannon, C. H. \& M. Lerdau. 2015. Variable mating behaviors and the maintenance of tropical biodiversity. Frontiers Genet. 6: 183.

Caron, H., J. F. Molino, D. Sabatier, P. Léger, P. Chaumeil, C. Scotti-Saintagne, J. M. Frigério, et al. 2019. Chloroplast DNA variation in a hyperdiverse tropical tree community. Ecology and Evolution. <https://doi.org/10.1002/ece3.5096>, accessed 30 July 2019.

de Casas, R. R., E. Cano, L. Balaguer, E. Pérez-Corona, E. Manrique, C. García-Verdugo \& P. Vargas. 2007. Taxonomic identity of Quercus coccifera L. in the Iberian Peninsula is maintained in spite of widespread hybridisation, as revealed by morphological, ISSR and ITS sequence data. Flora, Morphol. Distrib. Funct. Ecol. Pl. 202: 488-499.

Cavender-Bares, J. \& A. Pahlich. 2009. Molecular, morphological, and ecological niche differentiation of sympatric sister oak species, Quercus virginiana and Q. geminata (Fagaceae). Amer. J. Bot. 96: 1690-1702.

Chybicki, I. J. \& J. Burczyk. 2010. Realized gene flow within mixed stands of Quercus robur L. and Q. petraea (Matt.) L. revealed at the stage of naturally established seedling. Molec. Ecol. 19: 2137-2151.

Craft, K. J. \& M. V. Ashley. 2006. Population differentiation among three species of white oak in northeastern Illinois. Canad. J. Forest Res. 26: 206-215.

Crowl, A. A., P. S. Manos, J. D. McVay, A. R. Lemmon, E. M. Lemmon \& A. L. Hipp. 2019. Uncovering the genomic signature of ancient introgression between white oak lineages (Quercus). New Phytol. doi:10.1111/nph.15842.

Curtu, A., O. Gailing \& R. Finkeldey. 2007. Evidence for hybridization and introgression within a species-rich oak (Quercus spp.) community. BMC Evol. Biol. 7: 218.

Dodd, R. S. \& Z. Afzal-Rafii. 2004. Selection and dispersal in a multispecies oak hybrid zone. Evolution 58: 261-269.

Dumolin-Lapegue, S. A. K. \& R. J. Petit. 1999. Are chloroplast and mitochondrial DNA variation species independent in oaks? Evolution 53: 1406-1413.

Dumolin-Lapegue, S., B. Demesure, S. Fineschi, V. L. Come \& R. J. Petit. 1997. Phylogeographic structure of white oaks throughout the European continent. Genetics 146: 1475-1487.

Earl, D. A. \& B. M. vonHoldt. 2012. STRUCTURE HARVESTER: A website and program for visualizing STRUCTURE output and implementing the Evanno method. Conservation Genet. Resources 4: 359-361.

Eaton, D. A. R., A. L. Hipp, A. González-Rodríguez \& J. Cavender-Bares. 2015. Historical introgression among the American live oaks and the comparative nature of tests for introgression. Evolution 69: 2587-2601.

Ehrlich, P. R. \& P. H. Raven. 1969. Differentiation of populations: Gene flow seems to be less important in speciation than the neo-Darwinians thought. Science 165: 1228-1232.

Engelmann, G. 1876. The oaks of the United States. Trans. Acad. Sci. St. Louis 3: 539-543.

Evanno, G., S. Regnaut \& J. Goudet. 2005. Detecting the number of clusters of individuals using the software structure: A simulation study. Molec. Ecol. 14: 2611-2620.

Excoffier, L., P. E. Smouse \& J. M. Quattro. 1992. Analysis of molecular variance inferred from metric distances among DNA haplotypes: Application to human mitochondrial DNA restriction data. Genetics 131: 479-491.

Felsenstein, J. 2004. Inferring Phylogenies. Sinauer Associates, Inc., Sunderland, Massachusetts.

Fitzek, E., A. Delcamp, E. Guichoux, M. Hahn, M. Lobdell \& A. L. Hipp. 2018. A nuclear DNA barcode for eastern North American oaks and application to a study of hybridization in an arboretum setting. Ecol. Evol. 8: 5837-5851.

Gabriel, S., L. Ziaugra \& D. Tabbaa. 2009. SNP genotyping using the Sequenom MassARRAY iPLEX platform. Curr. Protoc. Human Genet. 60: 2.12.1-2.12.18.

Gailing, O. \& A. L. Curtu. 2014. Interspecific gene flow and maintenance of species integrity in oaks. Ann. Forest Res. 57: 5-18.

Goicoechea, P. G., A. Herran, J. Durand, C. Bodenes, C. Plomion \& A. Kremer. 2015. A linkage disequilibrium perspective on the genetic mosaic of speciation in two hybridizing Mediterranean white oaks. Heredity 114: 373-386.

Gömöry, D. \& J. Schmidtová. 2007. Extent of nuclear genome sharing among white oak species (Quercus L. subgen. Lepidobalanus (Endl.) Oerst.) in Slovakia estimated by allozymes. Pl. Syst. Evol. 266: 253-264.

Gray, A. 1857. Manual of the Botany of the Northern United States. Including Virginia, Kentucky, and all East of the Mississippi: Arranged According to the Natural System. G. P. Putnam \& Co., New York.

Gray, A. 1859. Manual of the Botany of the Northern United States: Including Virginia, Kentucky, and all East of the Mississippi Arranged According to the Natural System. Ivison \& Phinney, New York.

Gray, A. 1862. Manual of the Botany of the Northern United States, 3rd revised edition. Ivison, Phinney \& Co., Chicago.

Gray, A. 1867. Manual of the Botany of the Northern United States, Including the District East of the Mississippi and North of North Carolina and Tennessee, Arranged According to the Natural System. Ivison, Blakeman, Taylor \& Co., New York.

Gray, A. \& W. S. Sullivant. 1848. A Manual of the Botany of the Northern United States, from New England to Wisconsin and South to Ohio and Pennsylvania Inclusive (the Mosses and Liverworts by Wm. S. Sullivant) Arranged According to the Natural System. J. Munroe, J. Chapman, Boston and London.

Guichoux, E., P. Garnier-Géré, L. Lagache, T. Lang, C. Boury \& R. J. Petit. 2013. Outlier loci highlight the direction of introgression in oaks. Molec. Ecol. 22: 450-462. 
Hardin, J. W. 1975. Hybridization and introgression in Quercus alba. J. Arnold Arbor. 56: 336-363.

Hauser, D. A., A. Keuter, J. D. McVay, A. L. Hipp \& P. S. Manos. 2017. The evolution and diversification of the red oaks of the California Floristic Province (Quercus section Lobatae, series Agrifoliae). Amer. J. Bot. 104: 1581-1595.

Hipp, A. L. 2015. Should hybridization make us skeptical of the oak phylogeny? Int. Oak J. 26: 9-18.

Hipp, A. L. 2018. Pharaoh's dance: The oak genomic mosaic. PeerJ Preprints 6: E27405vl.

Hipp, A. L. \& J. A. Weber. 2008. Taxonomy of Hill's oak (Quercus ellipsoidalis: Fagaceae): Evidence from AFLP data. Syst. Bot. 33: 148-158.

Hipp, A. L., P. S. Manos, A. González-Rodríguez, M. Hahn, M. Kaproth, J. D. McVay, S. V. Avalos, et al. 2018. Sympatric parallel diversification of major oak clades in the Americas and the origins of Mexican species diversity. New Phytol. 217: 439-452.

Hipp, A. L., P. S. Manos, M. Hahn, M. Avishai, C. Bodénès, J. Cavender-Bares, A. Crowl, et al. 2019. Genomic landscape of the global oak phylogeny. bioRxiv <https://doi.org/ 10.1101/587253>, accessed 30 July 2019.

Jakobsson, M. \& N. A. Rosenberg. 2007. CLUMPP: A cluster matching and permutation program for dealing with label switching and multimodality in analysis of population structure. Bioinformatics 23: 1801-1806.

Kahle, D. \& H. Wickham. 2013. ggmap: Spatial visualization with ggplot2. R J. 5: 144-161.

Kenzo, T., K. Kamiya, K. M. Ngo, N. Faizu, S. K. Y. Lum, S. Igarashi, Y. Norichika, et al. 2019. Overlapping flowering periods among Shorea species and high growth performance of hybrid seedlings promote hybridization and introgression in a tropical rainforest of Singapore. Forest Ecol. Managem. 435: 38-44.

Kim, B. Y., X. Wei, S. Fitz-Gibbon, K. E. Lohmueller, J. Ortego, P. F. Gugger \& V. L. Sork. 2018. RADseq data reveal ancient, but not pervasive, introgression between Californian tree and scrub oak species (Quercus sect. Quercus: Fagaceae). Molec. Ecol. 27: 4556-4571.

Kremer, A. \& A. L. Hipp. Oaks: An evolutionary success story. New Phytol. (in press).

Leroy, T., C. Roux, L. Villate, C. Bodénès, J. Romiguier, J. A. P. Paiva, C. Dossat, et al. 2017. Extensive recent secondary contacts between four European white oak species. New Phytol. 214: 865-878.

Leroy, T., Q. Rougemont, J. L. Dupouey, C. Bodenes, C. Lalanne, C. Belser, K. Labadie, et al. 2018. Massive postglacial gene flow between European white oaks uncovered genes underlying species barriers. New Phytol. < https://doi.org/10.1111/nph.16039>, accessed 30 July 2019.

Lexer, C., A. Kremer \& R. J. Petit. 2006. Shared alleles in sympatric oaks: Recurrent gene flow is a more parsimonious explanation than ancestral polymorphism. Molec. Ecol. 15: 2007-2012.

Lind-Riehl, J. F., A. R. Sullivan \& O. Gailing. 2014. Evidence for selection on a CONSTANS-like gene between two red oak species. Ann. Bot. 113: 967-975.

Little, E. L. 1971. Conifers and Important Hardwoods, Vol. 1: Atlas of United States Trees. U.S. Department of Agriculture, Forest Service, Washington, D.C.

Little, E. L. 1977. Minor Eastern Hardwoods, Vol. 4: Atlas of United States Trees. U.S. Department of Agriculture, Forest Service, Washington, D.C.

Little, E. L. 1979. Checklist of United States Trees (Native and Naturalized). U.S. Department of Agriculture, Washington, D.C.
Manos, P. S., J. J. Doyle \& K. C. Nixon. 1999. Phylogeny, biogeography, and processes of molecular differentiation in Quercus subgenus Quercus (Fagaceae). Molec. Phylogen. Evol. 12: 333-349.

McVay, J. D., D. Hauser, A. L. Hipp \& P. S. Manos. 2017a. Phylogenomics reveals a complex evolutionary history of lobed-leaf white oaks in western North America. Genome 60: 733-742.

McVay, J. D., A. L. Hipp \& P. S. Manos. 2017b. A genetic legacy of introgression confounds phylogeny and biogeography in oaks. Proc. Biol. Sci. 284: 20170300.

Minckler, L. S. 1965. White oak (Quercus alba L.). Pp. 631-637 in Silvics of Forest Trees of the United States. Agriculture Handbook 271. U.S. Department of Agriculture, Washington, D.C.

Moran, E. V., J. Willis \& J. S. Clark. 2012. Genetic evidence for hybridization in red oaks (Quercus sect. Lobatae, Fagaceae). Amer. J. Bot. 99: 92-100.

Morjan, C. L. \& L. H. Rieseberg. 2004. How species evolve collectively: Implications of gene flow and selection for the spread of advantageous alleles. Molec. Ecol. 13: 1341-1356.

Muir, G. \& C. Schlötterer. 2005. Evidence for shared ancestral polymorphism rather than recurrent gene flow at microsatellite loci differentiating two hybridizing oaks (Quercus spp.). Molec. Ecol. 14: 549-561.

Muir, G. \& C. Schlötterer. 2006. Moving beyond single-locus studies to characterize hybridization between oaks (Quercus spp.). Molec. Ecol. 15: 2301-2304.

Muir, G., C. C. Fleming \& C. Schlötterer. 2000. Species status of hybridizing oaks. Nature (London) 405: 1016

Muller, C. H. 1952. Ecological control of hybridization in Quercus: A factor in the mechanism of evolution. Evolution 6: 147-161.

Ness, H. 1918. Hybrids of the live oak and overcup oak. J. Heredity 9: 263-268.

Nixon, K. C. 1997. Quercus. In Flora of North America Editorial Committee (editors), Flora of North America North of Mexico, Vol. 3. Oxford University Press, New York.

Oney-Birol, S., S. Fitz-Gibbon, J. M. Chen, P. F. Gugger \& V. L. Sork. 2018. Assessment of shared alleles in droughtassociated candidate genes among southern California white oak species (Quercus sect. Quercus). BMC Genet. 19: 88.

Owusu, S. A., A. R. Sullivan, J. A. Weber, A. L. Hipp \& O. Gailing. 2015. Taxonomic relationships and gene flow in four North American Quercus species (Quercus section Lobatae). Syst. Bot. 40: 510-521.

Palmer, E. J. 1948. Hybrid oaks of North America. J. Arnold Arbor. 29: 1-48.

Petit, R., E. Pineau, B. Demesure, R. Bacilieri, A. Ducousso \& A. Kremer. 1997. Chloroplast DNA footprints of postglacial recolonization by oaks. Proc. Natl. Acad. Sci. U.S.A. 94: 9996-10001.

Petit, R., C. Bodenes, A. Ducousso, G. Roussel \& A. Kremer. 2003. Hybridization as a mechanism of invasion in oaks. New Phytol. 161: 151-164.

Pham, K. K., A. L. Hipp, P. S. Manos \& R. C. Cronn. 2017. A time and a place for everything: Phylogenetic history and geography as joint predictors of oak plastome phylogeny. Genome 60: 720-732.

Plomion, C., J. M. Aury, J. Amselem, T. Leroy, F. Murat, S. Duplessis, S. Faye, et al. 2018. Oak genome reveals facets of long lifespan. Nat. Pl. 4: 440-452.

Prasad, A. M. \& L. R. Iverson. 2003. Little's Range and FIA Importance Value Database for 135 Eastern US Tree 
Species. Northeastern Research Station, USDA Forest Service, Delaware, Ohio.

Pritchard, J. K., M. Stephens \& P. Donnelly. 2000. Inference of population structure using multilocus genotype data. Genetics 155: 945-959.

R-Development-Core-Team. 2004. R: A language and environment for statistical computing. R Foundation for Statistical Computing, Vienna.

Rieseberg, L. H., T. E. Wood \& E. J. Baack. 2006. The nature of plant species. Nature (London) 440: 524-527.

Rosenberg, N. A. 2004. DISTRUCT: A program for the graphical display of population structure. Molec. Ecol. Notes 4: 137-138.

Scotti-Saintagne, C., S. Mariette, I. Porth, P. G. Goicoechea, T. Barreneche, C. Bodenes, K. Burg, et al. 2004. Genome scanning for interspecific differentiation between two closely related oak species. [Quercus robur L. and Q. petraea (Matt.) Liebl.] Genetics 168: 1615-1626.

Sokal, R. R. \& C. D. Michener. 1958. A statistical method for evaluating systematic relationships. Univ. Kansas Sci. Bull. 38: 1409-1438.
Sullivan, A. R., S. A. Owusu, J. A. Weber, A. L. Hipp \& O. Gailing. 2016. Hybridization and divergence in multispecies oak (Quercus) communities. Bot. J. Linn. Soc. 181: 99-114.

Tovar-Sánchez, E. \& K. Oyama. 2004. Natural hybridization and hybrid zones between Quercus crassifolia and Quercus crassipes (Fagaceae) in Mexico: Morphological and molecular evidence. Amer. J. Bot. 91: 1352-1363.

Urbanek, S. 2012. proj4: A simple interface to the PROJ.4 cartographic projections library.

Van Valen, L. 1976. Ecological species, multispecies, and oaks. Taxon 25: 233-239.

Whittemore, A. T. \& B. A. Schaal. 1991. Interspecific gene flow in sympatric oaks. Proc. Natl. Acad. Sci. U.S.A. 88: 2540-2544.

Wickham, H. 2009. ggplot2: Elegant Graphics for Data Analysis. Springer-Verlag, New York.

Wiegand, K. M. 1935. A taxonomist's experience with hybrids in the wild. Science 81: 161-166.

Yarnell, S. H. \& E. J. Palmer. 1933. Inheritance in an oak species hybrid. J. Arnold Arbor. 14: 68-75. 